\title{
Androgens and ovarian function: translation from basic discovery research to clinical impact
}

\author{
K A Walters 1,2, V Rodriguez Paris' ${ }^{1}$, A Aflatounian¹ and D J Handelsman² \\ 1School of Women's \& Children's Health, University of New South Wales, Sydney, New South Wales, Australia \\ ${ }^{2}$ Andrology Laboratory, ANZAC Research Institute, University of Sydney, Sydney, New South Wales, Australia
}

Correspondence should be addressed to K A Walters: k.walters@unsw.edu.au

\begin{abstract}
In the last decade, it has been revealed that androgens play a direct and important role in regulating female reproductive function. Androgens mediate their actions via the androgen receptor (AR), and global and cell-specific Ar-knockout mouse models have confirmed that AR-mediated androgen actions play a role in regulating female fertility and follicle health, development and ovulation. This knowledge, along with the clinical data reporting a beneficial effect of androgens or androgen-modulating agents in augmenting in vitro fertilization (IVF) stimulation in women termed poor responders, has supported the adoption of this concept in many IVF clinics worldwide. On the other hand, substantial evidence from human and animal studies now supports the hypothesis that androgens in excess, acting via the AR, play a key role in the origins of polycystic ovary syndrome (PCOS). The identification of the target sites of these AR actions and the molecular mechanisms involved in underpinning the development of PCOS is essential to provide the knowledge required for the future development of novel, mechanism-based therapies for the treatment of PCOS. This review will summarize the basic scientific discoveries that have enhanced our knowledge of the roles of androgens in female reproductive function, discuss the impact these findings have had in the clinic and how a greater understanding of the role androgens play in female physiology may shape the future development of effective strategies to improve IVF outcomes in poor responders and the amelioration of symptoms in patients with PCOS.
\end{abstract}

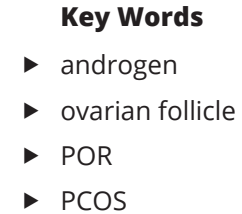

Journal of Endocrinology (2019) 242, R23-R50

\section{Introduction}

Androgens are sex steroid hormones that are well known to be crucial for male sexual and reproductive function. In females, androgens play an essential role in ovarian follicular development as testosterone is the obligatory estradiol (E2) precursor (Simpson et al. 2002). In descending order of serum concentrations, dehydroepiandrosterone sulfate (DHEAS), dehydroepiandrosterone (DHEA), androstenedione (A4), testosterone and dihydrotestosterone (DHT) are the major circulating androgens in women (Davison \& Davis 2003).
Androgens mediate their actions primarily via the androgen receptor (AR), which is a member of the nuclear receptor superfamily (Quigley et al. 1995). Classically, only the bioactive androgens, testosterone and DHT, bind directly to the AR, while the pro-androgens, DHEA and A4 require conversion to testosterone or DHT to exert androgenic effects (Burger 2002). However, recent reports have described direct effect of DHEA in the brain and vascular endothelial cells (Liu et al. 2008, Soma et al. 2015). 
AR mRNA and protein are expressed at all levels of the female hypothalamic-pituitary-gonadal (HPG) axis, including the brain, ovarian stroma, ovarian follicles and corpora lutea (Walters \& Handelsman 2018). AR expression is present in fetal (Wilson \& McPhaul 1996) and in adult (Suzuki et al. 1994) ovaries and has been identified in the majority of ovarian follicular stages, but with differential temporal and special patterns of expression, indicating distinct roles for AR-mediated actions during different stages of follicular development. In general, AR expression is present as follicles enter the growing pool, AR immunostaining is observed in the oocyte, granulosa cells and theca cells of preantral follicles, but during antral follicular growth, AR expression progressively declines in the outer mural granulosa cells but remains intense in the cumulus cells (Szoltys \& Slomczynska 2000, Lenie \& Smitz 2009) (Fig. 1). Interestingly, both phosphorylated and non-phosphorylated forms of $\mathrm{AR}$ have been detected in primate ovarian granulosa cells of developing follicles, inferring that apart from de novo synthesis, phosphorylation of AR may also regulate receptor levels and function (McEwan et al. 2010). Moreover, ovarian AR expression across numerous mammalian species (mouse; Lenie \& Smitz 2009, rat; Szoltys \& Slomczynska 2000, sheep; Juengel et al. 2006, pig; Slomczynska \& Tabarowski 2001, cow; Hampton et al. 2004, primate; Hild-Petito et al. 1991 and human; Horie et al. 1992, Nielsen et al. 2011) is evolutionarily conserved, supporting a universal role for AR-mediated androgen actions on the function of the ovary.

\section{Defining poor ovarian response (POR) patients and evidence to support the use of androgens or androgen-modulating agents in POR patients undergoing IVF}

\section{Characteristics of poor ovarian response}

As women age, there is a progressive decline in the number of oocytes in the ovaries, and this correlates with an agerelated decrease in fecundity. This reduction in fertility is greatest in women in their late 30s and early 40s, with menopause and natural reproductive sterility reached

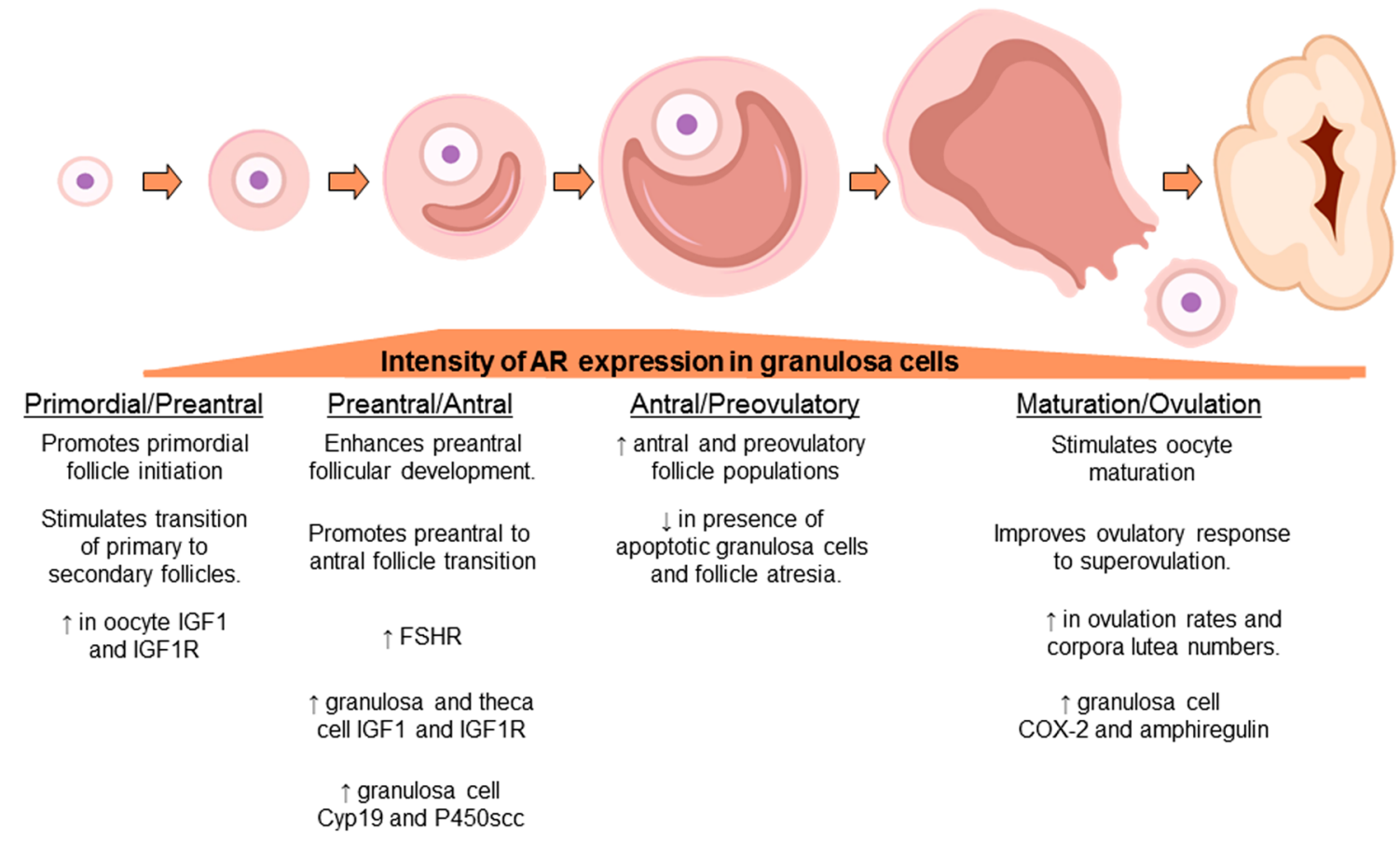

Figure 1

Pattern of androgen receptor (AR) expression and the impact of androgen exposure on ovarian dynamics at different stages of follicle development. AR expression in granulosa cells is first detected as follicles enter the growing pool and remains detectable throughout follicle development. In general, the intensity of AR expression in granulosa cells follows a gradient pattern during follicle development. AR expression increases to the antral stage and then progressively declines in the outer mural granulosa cells of antral follicles, but remains intense in the cumulus cells surrounding the oocyte (pattern of AR immunostaining observed in several species including porcine (Slomczynska \& Tabarowski 2001) and mice (Lenie \& Smitz 2009)). Overall, androgens have a stimulatory role on follicle development, with their actions observed to optimize follicle growth, follicle health and ovulation. COX-2, cyclo-oxygenase; FSHR, follicle-stimulating hormone receptor; IGF1, insulin-like growth factor 1; IGF1R, insulin-like growth factor 1 receptor. 
at an average age of 51 years. Along with this observed decline in the quantity of oocytes, the quality and the competence of the oocytes to result in a live birth also diminishes as women age (Homan et al. 2007). As a result, women aged 35-39 years of age have a 50\% reduced chance of conceiving spontaneously when compared to 19-25 year old women (Taylor 2003). Inevitably, as more couples are delaying the start of their family until women are in their late 30s, the number of couples seeking infertility treatment options has increased. IVF is a key assisted reproductive technology (ART); however, a notable proportion of women undergoing IVF treatments fail to have an adequate ovarian response to the hormonal stimulation (Tarlatzis et al. 2003). Age is known to be the main correlated risk factor for poor ovarian response (POR) (Ferraretti et al. 2011). This is not only because of the diminished follicular pool in the ovaries of aged women (Gougeon 1996), but also as a result of the declined ovarian response to follicle-stimulating hormone (FSH) with advancing age (Goverde et al. 2005).

Numerous definitions have been applied to define POR in women undergoing IVF (Polyzos \& Devroey 2011); however, the Bologna criteria was the first sound attempt to form an international accepted consensus on the definition of POR (Ferraretti et al. 2011). According to the Bologna criteria, a women is defined as having POR if at least two of the following features are present: advanced maternal age ( $\geq 40$ years of age) or any other risk factor for POR; a previous POR ( $\leq 3$ oocytes with a conventional ovarian stimulation protocol) and/or an abnormal ovarian reserve test (i.e. antral follicle count (AFC) $<5-7$ follicles or anti-Müllerian hormone $(\mathrm{AMH})<0.5-1.1 \mathrm{ng} / \mathrm{mL})$.

\section{Clinical evidence indicating the need for optimized androgen levels during follicle development}

FSH and luteinizing hormone (LH) secreted from the pituitary act on the ovary to stimulate the production of androgens in theca cells and estrogen synthesis in granulosa cells (Hillier et al. 1994) (Fig. 2). Circulating levels of pro-androgens (DHEAS, DHEA, A4) and the bioactive androgen testosterone have been reported to decline with age (Zumoff et al. 1995, Davison et al. 2005). This decline is reported to be steepest in the early reproductive years, with no significant effect of natural menopause on circulating androgen levels, unlike E2 which displays a sharp decline at this time (Davison et al. 2005). This decline in androgen levels with age has been proposed to potentially contribute or reflect the diminishing ability of the aging ovary to respond to FSH-based stimulation in IVF.
As such, it has been suggested that the bioavailability of androgens within the ovary may increase follicular response. Several studies have reported on whether serum androgen levels can predict ovarian response or IVF outcomes. In normal cycling women, there is a positive correlation between free androgen index and total ovarian follicle count following ovarian hyperstimulation (Dickerson et al. 2010). Similarly, serum testosterone levels have been described to positively correlate with ovarian response (Barbieri et al. 2005, Sun et al. 2014, Xiao et al. 2016) and pregnancy outcomes (Frattarelli \& Peterson 2004, Lu et al. 2014) in IVF, inferring that a lower level of testosterone may relate with a poorer ovarian response (Sun et al. 2014, Xiao et al. 2016) and a decreased success in achieving a pregnancy. However, studies often do not report a consistent correlation between serum androgen levels and IVF reproductive outcomes (Lu et al. 2014, Sun et al. 2014, Xiao et al. 2016). Additionally, in a more recent study using highly sensitive and specific liquid chromatography-mass spectrometry methods, androgen levels in either serum or follicular fluid from the dominant follicle did not predict IVF outcomes (Walters et al. 2019).

\section{Clinical and animal studies supporting a beneficial role for androgens in follicle development}

Clinical conditions where excessive levels of androgens are present in women, such as congenital adrenal hyperplasia (Lucis et al. 1966), testosterone-treated female-to-male transsexuals (Becerra-Fernandez et al. 2014) and PCOS (Dumesic et al. 2015) have revealed that elevated levels of androgens stimulate early follicle development but then lead to arrested antral follicle development, as all of these patient groups have been reported to exhibit polycystic-like ovaries. Confirmation of an influence of androgens from the early stages of follicle development comes from animal studies where the bioactive androgens testosterone and DHT in mice (Yang et al. 2010) and primates (Vendola et al. 1999) stimulate primordial follicle initiation. AR gene expression in several species is most abundant in the granulosa cells of healthy growing follicles (Walters \& Handelsman 2018). Various androgens (testosterone, A4, DHEA and DHT) also significantly promote preantral to antral follicle growth in mice (Murray et al. 1998, Wang et al. 2001), sheep (Narkwichean et al. 2014) and primates (Vendola et al. 1998). These effects were confirmed to be due to direct AR-mediated actions as the observed stimulatory effects in mice were blocked by an AR antagonist bicalutamide (Murray et al. 1998). 


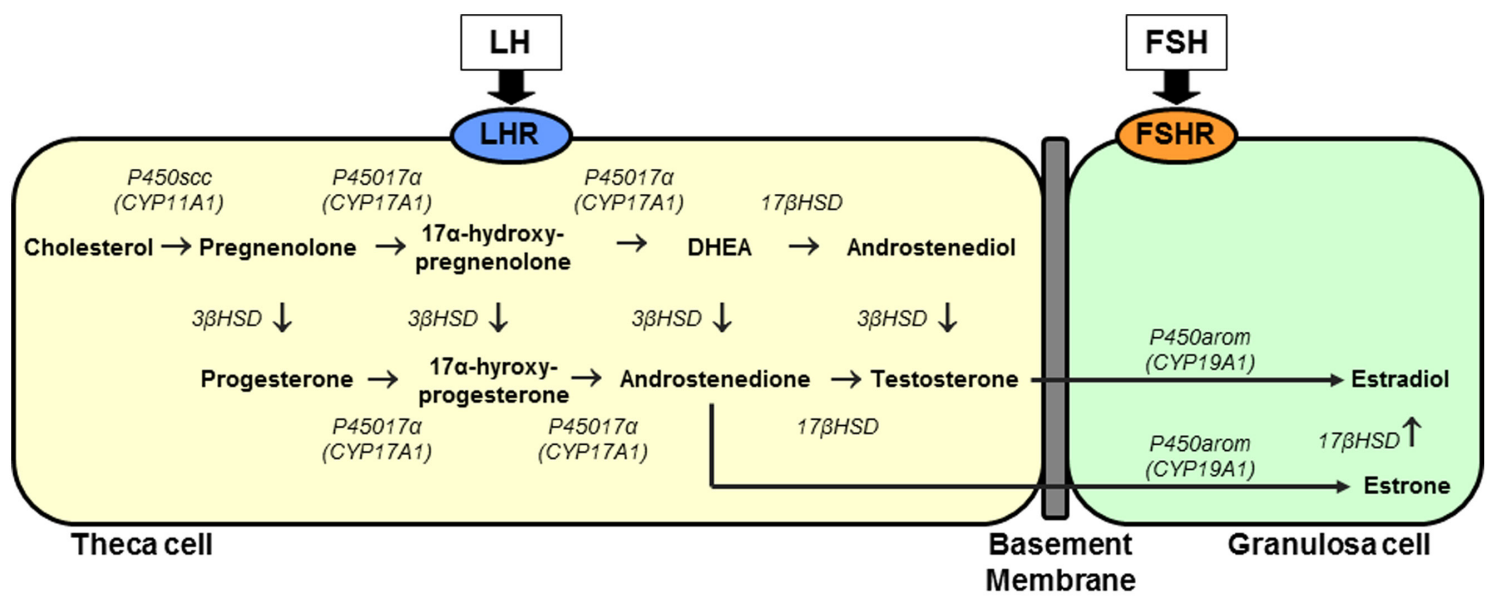

Direct androgen actions

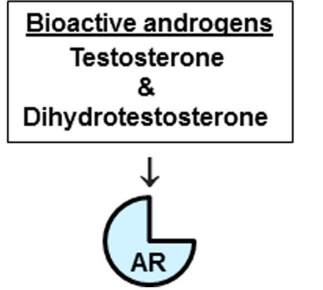

Indirect androgen actions

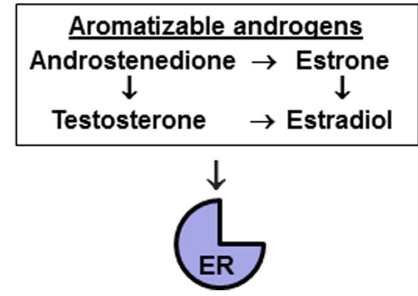

Figure 2

Androgen biosynthesis in rodent ovarian follicles and different modes of androgenic actions. Androgens synthesis and metabolism occur in the theca and granulosa cells of the ovarian follicle. In comparison to rodents, in primates, including humans, progesterone is not a source for androgen biosynthesis as CYP17A1 does not convert 17 $\alpha$-hydroxyprogesterone to androstenedione. Theca cells from sheep, humans and primates principally produce androstenedione, whereas rodents produce testosterone as precursors for estradiol production in the neighboring granulosa cells. Androgens can mediate their actions directly via the androgen receptor (AR), or indirectly by their conversion into estrogens and $3 \beta$-diol, both of which can interact with the estrogen receptor (ER). 3 $\beta$ HSD, 3- $\beta$-hydroxysteroid dehydrogenase; $17 \beta$-hydroxysteroid dehydrogenase; $3 \beta$-diol, $5 \alpha$-androstane-3 $\beta, 17 \beta$-diol; $3 \alpha$-diol, $5 \alpha$-androstane- $3 \alpha, 17 \beta$-diol.

There is also evidence supporting a synergistic interaction between androgens and FSH in the regulation of follicle growth, which has obvious significance in terms of hormonal ovarian stimulation regimes during IVF. Testosterone and DHT treatment in a mouse in vitro culture system enhances FSH-mediated preantral to antral follicle development in a dose-dependent manner (Sen et al. 2014, Laird et al. 2017), with effects reversed by an AR antagonist flutamide (Laird et al. 2017). Moreover, findings from rat (Hillier \& De Zwart 1981) and primate (Harlow et al. 1986) in vitro granulosa cell cultures have demonstrated that androgens can modulate FSH-induced steroidogenesis. FSH receptor mRNA expression in primate primary follicles increased following treatment with testosterone (Weil et al. 1999), while treatment with DHT or testosterone increased FSH receptor protein expression in growing mouse follicles (Sen et al. 2014, Laird et al. 2017). Similarly, both $A R$ mRNA expression in granulosa cells and androgen levels in follicular fluid collected from human small antral follicles showed a highly significant positive association with the expression of FSH receptor mRNA in granulosa cells. These findings suggest that follicular sensitivity to FSH stimulation may be augmented by androgen stimulation mediated via the AR. Indeed, responsiveness of follicles to FSH was enhanced when mouse preantral follicles were cultured in the presence of testosterone (Wang et al. 2001).

Several studies also indicate that the mechanisms regulating oocyte maturation and ovulation in the late stages of follicle development can also be influenced by androgens. In vitro germinal vesicle breakdown (GVBD) in mouse (Gill et al. 2004) and pig (Li et al. 2008) oocytes is enhanced in the presence of testosterone, with effects lost after the addition of the AR blocker flutamide. However, the level of androgen exposure appears to be important, as mouse oocyte meiotic competence was reduced by elevated levels of testosterone and A4 (Romero \& Smitz 2010). Preovulatory follicle and corpora lutea numbers 
were increased after pigs were treated with testosterone or DHT during the late follicular phase (Cárdenas \& Pope 1994, Cardenas et al. 2002). This effect on ovulatory processes appears to be AR mediated as treatment with the AR antagonist cyproterone acetate, decreased ovulations in mice (Sen et al. 2014) and rats (Kumari et al. 1978). However, again androgen levels appear to be important as low but not high doses of DHT were found in mice to enhance the ovulatory response to superovulation (Sen et al. 2014). Similarly, in a mouse in vitro culture system, AR-mediated effects on follicle growth and antrum formation display a biphasic pattern, with low doses of androgens stimulating rapid follicle maturation but high doses inhibiting oocyte maturation and follicle growth (Lebbe et al. 2017).

\section{Confirmation from AR-knockout (ARKO) mouse models of a role for androgens in follicle development}

Pharmacological studies have proved to be extremely informative in elucidating the role of androgens in ovarian function; however, they have often led to confusion when defining the mechanism by which the actions are mediated. This is due to the fact that aromatizable androgens can be converted into estrogens, and the non-aromatizable androgen DHT can be reduced into 3 3 -diol, all of which have the potential to exert indirect actions via the estrogen receptor (ER) (Hillier et al. 1994, Steckelbroeck et al. 2004) (Fig. 2). Moreover, while AR antagonists are useful tools they too can lead to difficulty in deciphering the precise mechanism, similar to all steroid blockers, AR antagonists are often mixed partial agonists/antagonist rather than pure blockers. However, with the advent of Cre/LoxP technologies (Kuhn \& Torres 2002) and the generation of global and cell-specific AR-knockout mouse models, key roles for androgen actions and detailed insights into the precise AR-mediated mechanisms involved in regulating female reproduction have been revealed (Table 1).

To date, three global androgen receptor-knockout (ARKO) mouse models have been generated with targeted deletions of exon 1 (ARKO ${ }^{\mathrm{Ex} 1}$ ) (Shiina et al. 2006), exon 2 $\left(\mathrm{ARKO}^{\mathrm{Ex} 2}\right.$ ) (Hu et al. 2004) or exon 3 (ARKO ${ }^{\mathrm{Ex} 3}$ ) (Walters et al. 2007) of the $A r$ gene. Subfertility, observed as fewer pups per litter, and dysfunctional ovarian follicle development are observed in all three of the different global ARKO mouse models (Yeh et al. 2002, Hu et al. 2004, Shiina et al. 2006, Walters et al. 2007). Hence, these models have confirmed a role for AR-mediated actions in ovarian follicle development and female fertility. A loss of AR actions leads to elevated levels of follicular atresia (Yeh et al. 2002, Hu et al. 2004, Shiina et al. 2006, Walters et al. 2007) and an alteration in key regulators of follicle health, evident by the observed reduction in ovarian expression of FSH and IGF1 receptors (Hu et al. 2004). In particular AR actions appear to play a crucial role during the later stages of follicle development as in global ARKO females, fewer preovulatory follicles are present, oocytes loose contact with surrounding cumulus cells and corpora lutea numbers are reduced, confirming reduced ovulation rates ( $\mathrm{Hu}$ et al. 2004, Shiina et al. 2006, Walters et al. 2007, Cheng et al. 2013). Expression of several important regulatory genes have also been identified as being disrupted during these late stages by the loss of AR signaling, including hyaluronan synthase 2 (Hu et al. 2004), tumour necrosis factor- $\alpha$-stimulated gene 6 (Hu et al. 2004), KIT ligand (Shiina et al. 2006), bone morphogenetic protein 15 (Shiina et al. 2006) and growth differentiation factor 9 (Shiina et al. 2006).

The involvement of AR signaling in the different ovarian cell types has been revealed by characterization of granulosa cell-specific ARKO (GCARKO) (Sen \& Hammes 2010, Walters et al. 2012b), theca cell-specific (TCARKO) (Ma et al. 2017) and oocyte-specific ARKO (OoARKO) (Sen \& Hammes 2010) mouse models. Two different GCARKO models have been reported with targeted deletions of exon 2 (GCARKO ${ }^{\mathrm{Ex} 2}$ ) (Sen \& Hammes 2010) and exon 3 (GCARKO $^{\mathrm{Ex} 3}$ ) (Ma et al. 2017). Similar to global ARKO mice, GCARKO females mice exhibited subfertility (Sen \& Hammes 2010, Walters et al. 2012b), and granulosa cell AR actions appear to play an important role in maintaining normal follicular growth and health as GCARKO ovaries display signs of defective follicle development reduced follicle health (Sen \& Hammes 2010, Walters et al. 2012b). These results confirm that granulosa cells are a key site for androgenic actions regulating female reproductive function. On the other hand, AR signaling within theca cells and oocytes do not appear to significantly influence ovarian function as both TCARKO and OoARKO females display normal estrous cycle patterns and fertility (Sen \& Hammes 2010, Ma et al. 2017). However, it should be noted that low levels of $A r$ mRNA expression were identified in both the TCARKO (Ma et al. 2017) and OoARKO (Sen \& Hammes 2010) models, indicating that potentially the contribution of AR theca cell and oocyte actions to ovarian function may be underestimated in these mouse models.

Along with a direct role for $\mathrm{AR}$ actions within the ovary, it is now clear that AR signaling across the 


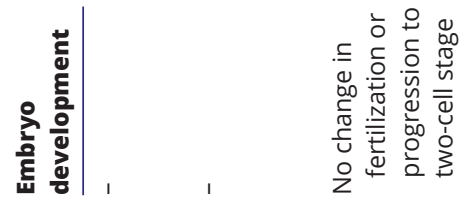

4.
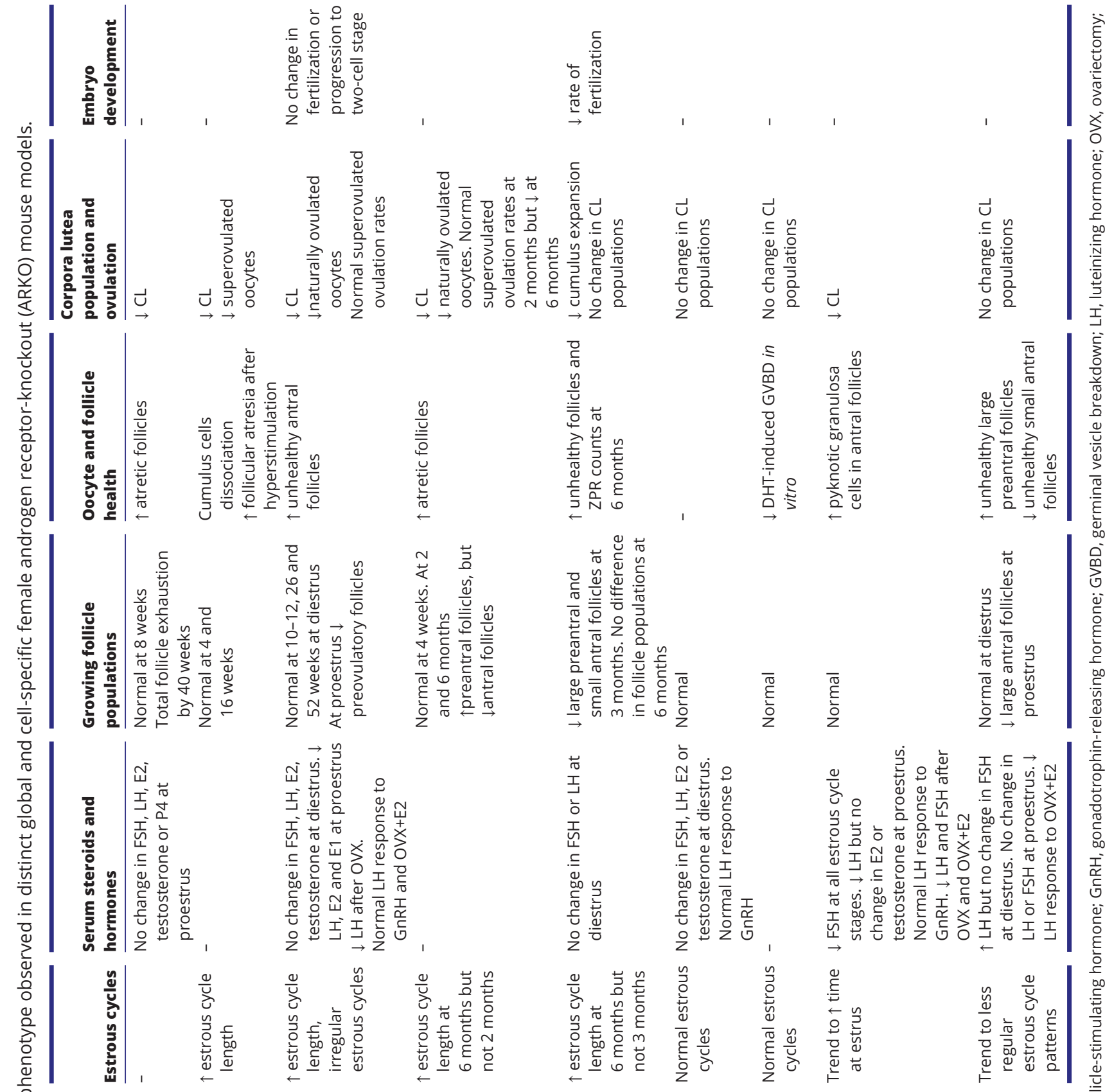

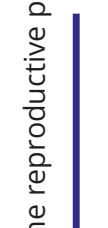
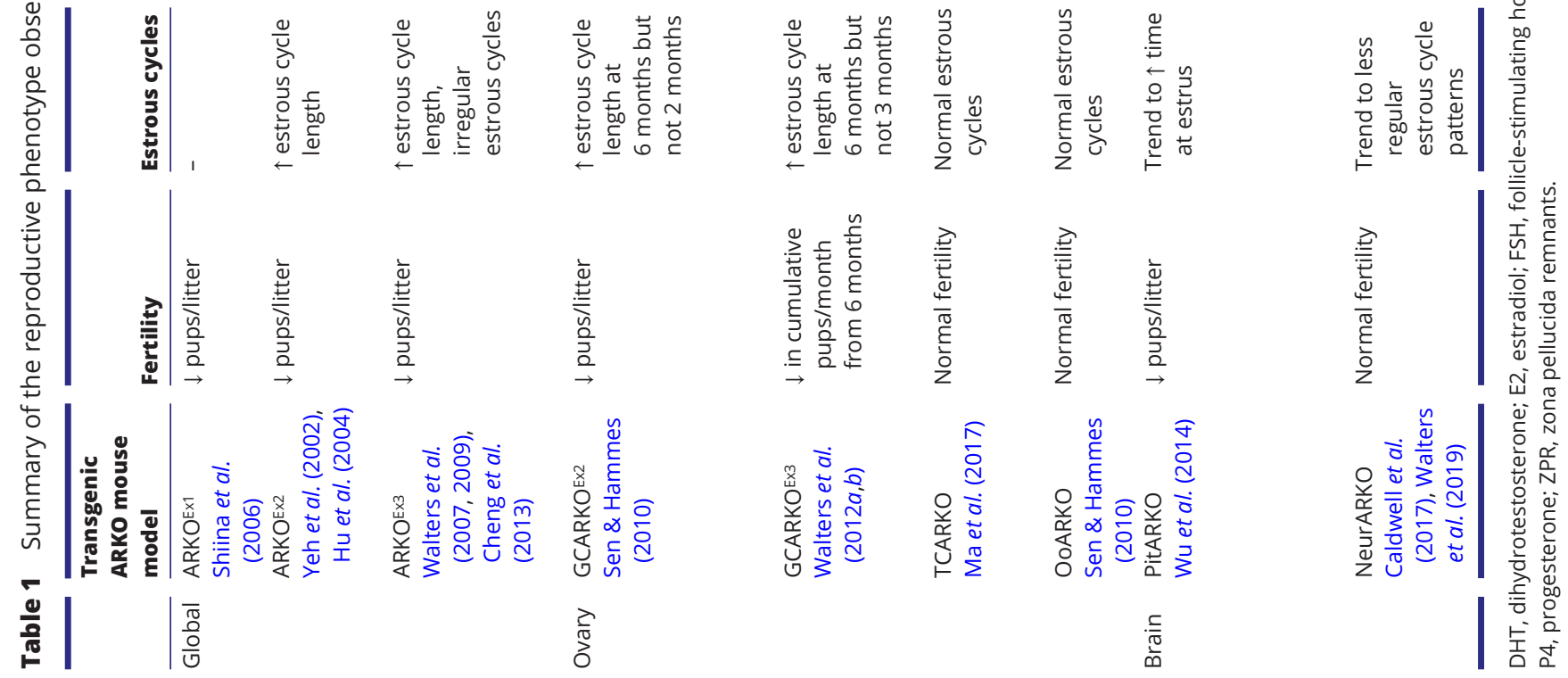
HPG axis is required to maintain normal female reproductive function. Strong evidence to support this initially came from the observation that transplantation of ovaries from a global ARKO or control female into an ovariectomized control host, caused no change in estrous cycle or fertility in the host (assessed by percentage of females to undergo a successful pregnancy and the number of litters per female). On the other hand, transplantation of ovaries from a control female into an ovariectomized global ARKO female, led to disrupted estrous cycles and reduced fertility in the host (Walters et al. 2009). Subsequently, transgenic mouse models exhibiting a loss of AR signaling in the pituitary (PitARKO) (Wu et al. 2014) or in the brain and pituitary (NeurARKO) (Caldwell et al. 2017, Walters et al. 2018b) have been generated and have confirmed a role for neuroendocrine AR actions in the regulation of the ovarian follicle dynamics. PitARKO females are subfertile, which appears to be due to the defects during late stages of follicle development as PitARKO ovaries display reduced antral follicle health and fewer corpora lutea (Wu et al. 2014). Surprisingly a loss of AR signaling in the neurons did not alter female fertility (Walters et al. 2018b). This inconsistency may be explained by the potential hypothyroidism in the PitARKO model due to this model being created by the use of gonadotrophin alpha subunit ( $\alpha$ GSU)-Cre that is expressed in not only pituitary gonadotropes but also the thyrotropes. However, NeurARKO females also display altered follicle development with reduced preantral and antral follicle health and large antral follicle numbers at proestrus (Caldwell et al. 2017, Walters et al. 2018b). Moreover, NeurARKO females exhibited aberrant neuroendocrine control with females displaying elevated LH levels at diestrus, a compromised serum LH response to ovariectomy and E2 priming and reduced Kiss 1 mRNA expression in the anteroventral periventricular nucleus, but elevated Kiss1 and neurokinin B mRNA expression in the arcuate nucleus at proestrus (Walters et al. 2018b).

\section{Use of androgens or androgen-modulating agents in POR patients undergoing IVF}

For women who have responded poorly to ovarian stimulation, the challenge is how to increase their response in future cycles, as there is no evidencebased standard of care. The majority of findings from basic discovery research support a stimulatory role for androgens in early follicle growth (Fig. 1), maintenance of follicle health and priming of the follicle during the later stages of development. Based on this, it has been put forward that there is strong evidence to support the current, but still unproven, notion of administration of androgen pre-treatment to POR patients undergoing IVF, with the aim of enhancing their follicular response to IVF hyperstimulation. The use of androgen pre-treatments is now undertaken in IVF centers worldwide, with one study claiming that one-third of all IVF centers use DHEA supplementation (Gleicher \& Barad 2011). At present three modes of treatment have been trialed clinically to increase androgen levels in POR IVF patients, including (i) systemic androgen administration (DHEA or testosterone), (ii) stimulation of endogenous androgen production in theca cells by LH or human chorionic gonadotrophin (hCG) and (iii) administration of an aromatase inhibitor (letrozole) to increase androgen levels by preventing the conversion of androgens into estrogens.

\section{Androgen administration}

\section{Dehydroepiandrosterone (DHEA)}

Androgen pre-treatment therapy originated following a 2000 report of a small, uncontrolled investigation where administration of DHEA ( $80 \mathrm{mg} /$ day) for 2 months prior to ovarian stimulation in five women with a previous history of POR was claimed to improve the ovarian response even after controlling for gonadotrophin dose (Casson et al. 2000). Subsequently, following DHEA treatment, a case study reported that a 43-year-old woman had an increase in her oocyte yield from initially 1 to up to 17 oocytes in subsequent cycles (Barad \& Gleicher 2005), and in a larger self-controlled study, ovarian response and fertilization rate were reported to significantly improve (Barad \& Gleicher 2006). These findings put forward the proposal that androgen supplementation may represent a novel way to enhance ovarian response.

Barad et al. followed up their observations in 2005 (Barad \& Gleicher 2005) and 2006 (Barad \& Gleicher 2006) with a much larger case-control study in 2007, which evaluated the efficacy of DHEA pre-treatment $(75 \mathrm{mg} /$ day for 4 months) in 190 patients (Barad et al. 2007). Analysis revealed a beneficial effect of DHEA treatment on ovarian response with an increased number of oocytes recovered and a significantly higher clinical pregnancy rate in DHEA-treated patients (Barad et al. 2007). Numerous investigations have now reported on the efficacy of DHEA pre-treatment in woman who exhibit POR (Table 2). In the majority of studies, a similar dose (75 mg/day) and treatment duration ( $\sim 3$ months) have been used, but the number of patients assessed (1-386 women) and the 


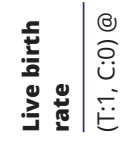

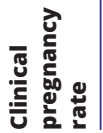

|

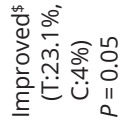

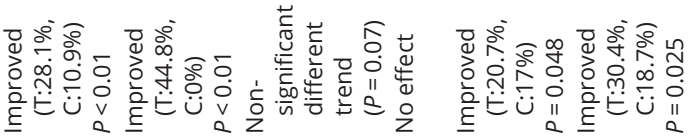

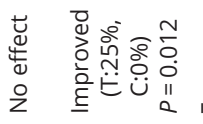

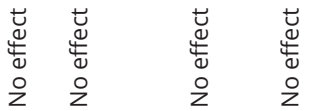

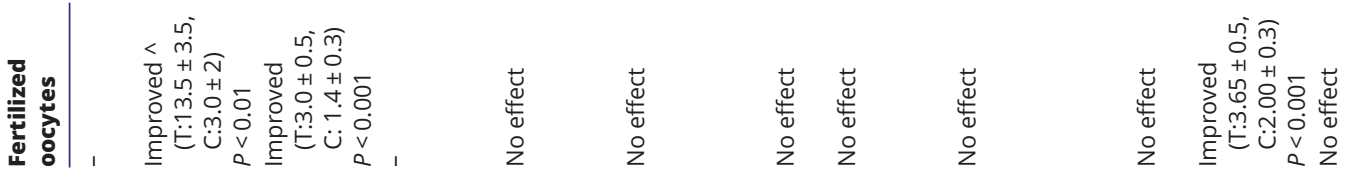
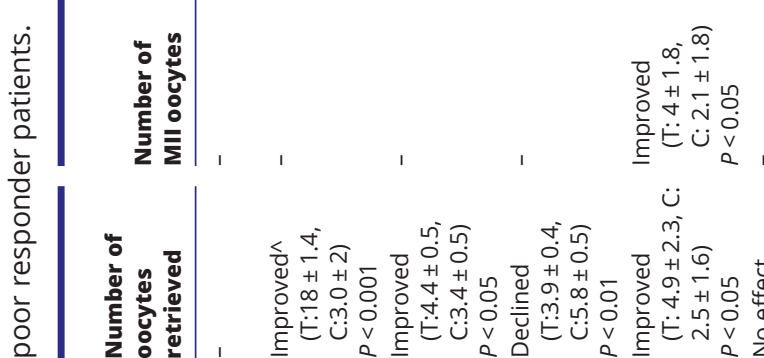

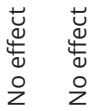

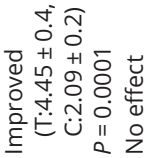

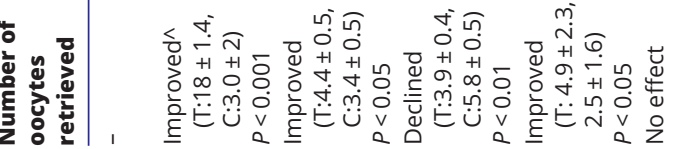

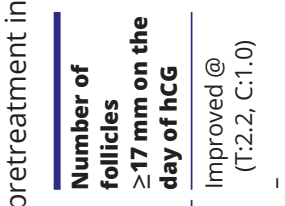

Eن

0
0
0

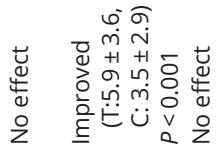

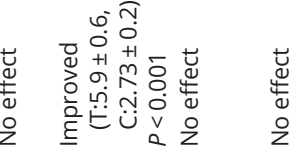

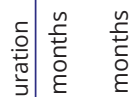

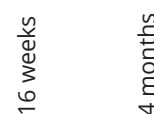

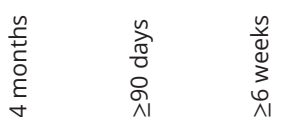

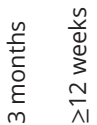

$\stackrel{n}{\frac{\pi}{0}}$
$\frac{0}{2}$

กัฒ

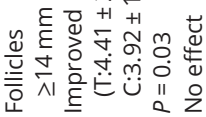

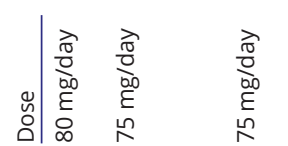

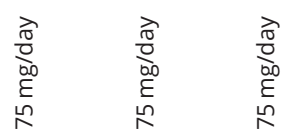

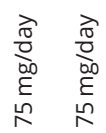

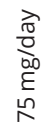

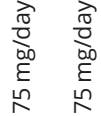

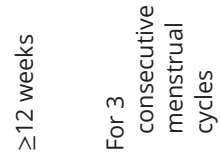

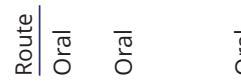

$\frac{0}{\frac{\pi}{0}} \sqrt{\frac{\pi}{0}}$

ब

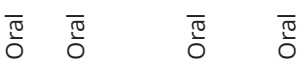

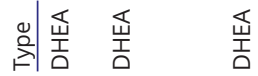

荘崖 荘

㟧 㟧

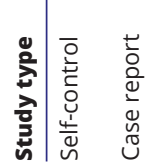

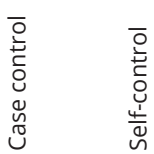

竞

施

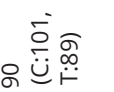

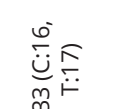

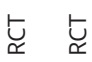

岌

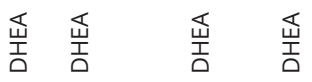

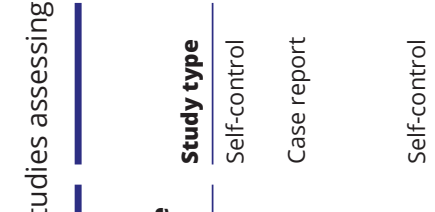

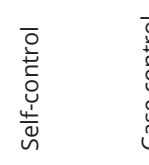

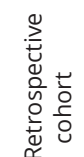

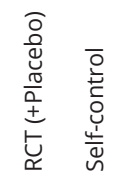

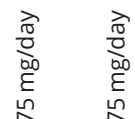

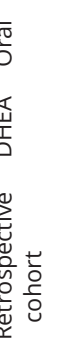

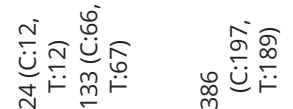

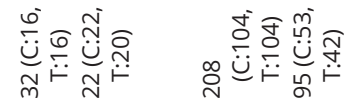

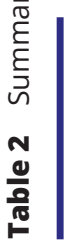
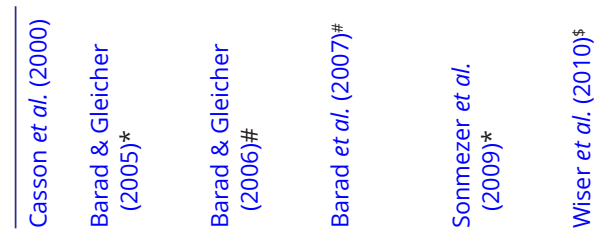

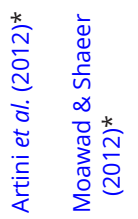

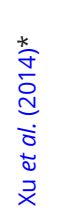

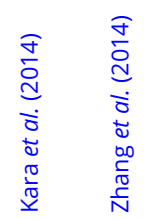




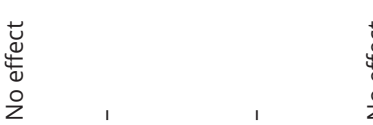

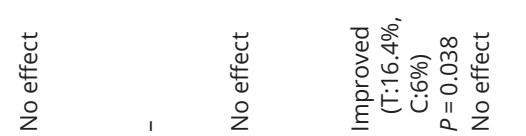

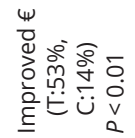

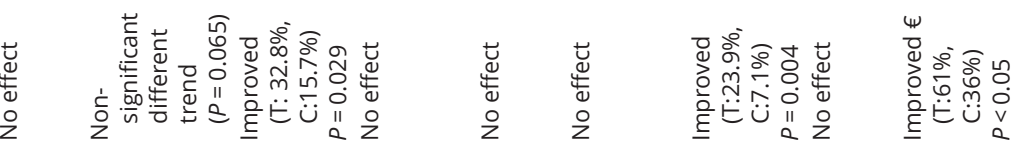

亲

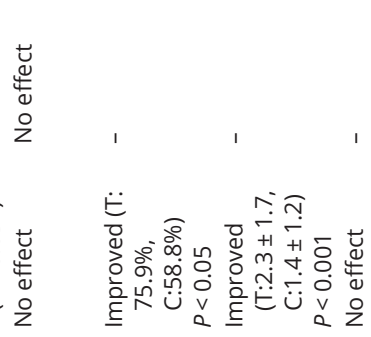

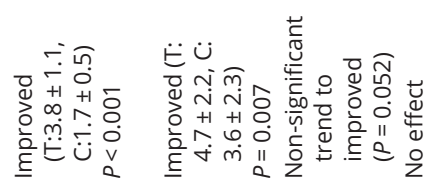

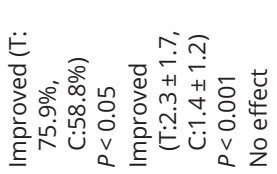

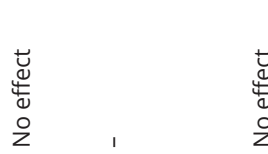

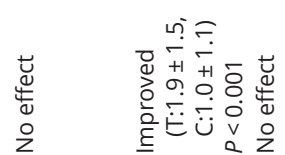

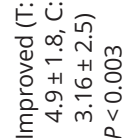

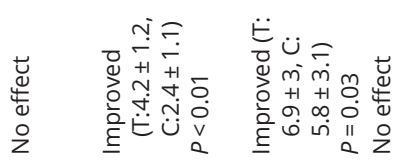

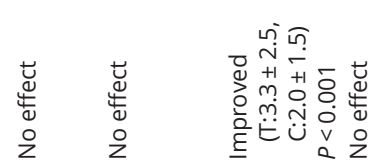

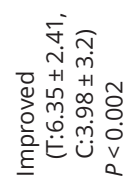

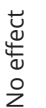

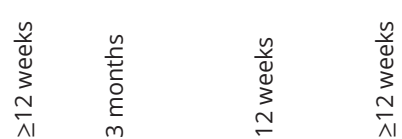

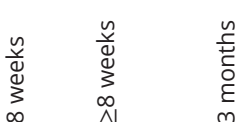

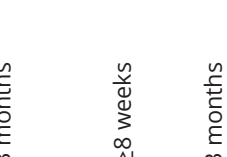

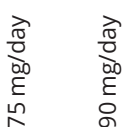

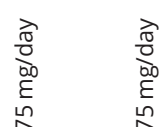

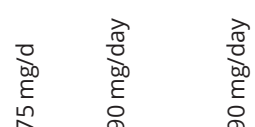

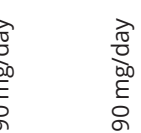

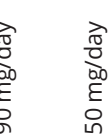

ฮั

बृ.

ฮั

$\overline{0}$

壵㞺

岌崖

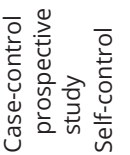

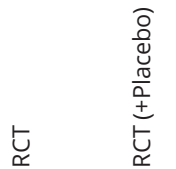

㜽

పั

$\frac{0}{2}$

岌㜽

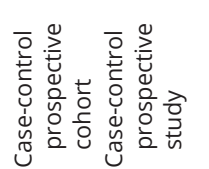

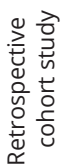

堊㠇

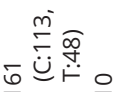

总众

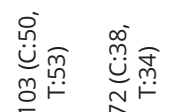

家

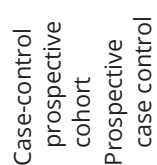

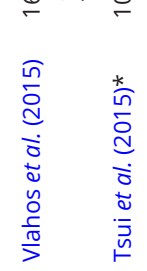

过

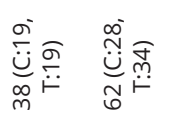

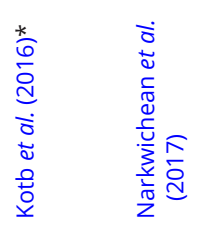

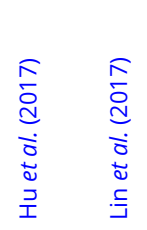

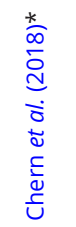

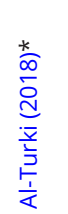


type of studies undertaken varies. Studies have reported that DHEA administration has improved antral follicle numbers, oocyte retrieval numbers, fertilization rates, embryo implantation rates, embryo quality, clinical pregnancy rates and live birth rates in some women (observations from studies summarized in Table 2). However, there are also a noteworthy number of studies, including well-designed placebo-controlled randomized control trials (RCTs), which have reported no consistent improvement in any endpoints assessed after exposure of women to DHEA prior to ovarian stimulation (Artini et al. 2012, Yeung et al. 2014, Kara et al. 2014, Zhang et al. 2014, Vlahos et al. 2015, Hu et al. 2017, Narkwichean et al. 2017, Li et al. 2018).

In an attempt to determine in POR patients if the use of DHEA pre-treatment increases the likelihood of improved ovarian response and ultimately a live birth, several groups have published systematic reviews and meta-analysis on the current literature. In the most recent systematic reviews and meta-analysis reporting on data from 5 to 21 studies, there is evidence to support the use of pre-IVF DHEA treatment in patients with POR, based on the finding that in all these studies, DHEA supplementation was associated with a significant increase in clinical pregnancy rate (Ji et al. 2016, Zhang et al. 2016, Hu et al. 2018, Schwarze et al. 2018) In addition, in some pooled analysis studies DHEA treatment was also significantly associated with an increase in antral follicle count (Zhang et al. 2016), the number of retrieved oocytes (Ji et al. 2016), endometrial thickness (Hu et al. 2018), implantation rate (Zhang et al. 2016) and live birth rates (Zhang et al. 2016, Hu et al. 2018).

\section{Testosterone}

Reports have also assessed the efficacy of administering the bioactive androgen, testosterone, in POR patients to improve ovarian response and IVF outcomes (Table 3). Although four RCTs (two with placebo controls) assessing the impact of transdermal testosterone administration for 5-20 days in POR patients showed no significant effect of testosterone pre-treatment (Massin et al. 2006, Fabregues et al. 2009, Sipe et al. 2010, Bosdou et al. 2016), since then numerous studies, including a placebo-controlled RCT, have reported on a range of beneficial effects of pre-IVF testosterone pre-treatment (Balasch et al. 2006, Kim et al. 2011, 2014, Mitri et al. 2016, Doan et al. 2017, Saharkhiz et al. 2018). These beneficial effects include improved antral follicle numbers, oocyte retrieval numbers, fertilization rates, embryo implantation rates, embryo quality, clinical pregnancy rates and live birth rates in some women (observations from studies summarized in Table 3).
Reasons suggested for the absence of any benefit of testosterone treatment in some studies have included differences in the timing and duration of androgen treatment. In contrast to studies which used DHEA pre-treatment, studies which assessed the efficacy of testosterone pre-treatment vary widely in the dose used $(2.5-25 \mathrm{mg} /$ day) and the duration of exposure (4-5 days - 4 weeks), making comparison between studies difficult. Kim et al. conducted a pilot controlled study with the aim to investigate the effect of transdermal testosterone gel in POR patients exposed for 2, 3 or 4 weeks prior to their IVF cycle (Kim et al. 2014). Interestingly, while testosterone pre-treatment for 2 weeks failed to show any significant effects, patients treated for 3 and 4 weeks exhibited a significantly improved ovarian response to hyperstimulation, but only patients exposed for 4 weeks displayed a significant increase in clinical pregnancy and live birth rates (Kim et al. 2014). Systematic reviews and meta-analysis have reported that POR patients may benefit from the use of testosterone pre-treatment transdermal. This is based on the evidence that testosterone pretreatment significantly increased the number of oocytes retrieved (Bosdou et al. 2012, Luo et al. 2014, Noventa et al. 2019) and clinical pregnancy and live birth rates (Bosdou et al. 2012, Gonzalez-Comadran et al. 2012, Luo et al. 2014, Jeve \& Bhandari 2016, Noventa et al. 2019).

\section{Use of androgen-modulating agents}

\section{Aromatase inhibitors}

Letrozole, an aromatase inhibitor, has also been trialed as a potential way to improve IVF outcomes in poor responders as inhibition of aromatase activity would subsequently increase levels of androgens by blocking their aromatization to estrogens. In a preliminary selfcontrolled report on 12 patients with unexplained infertility and previous poor response treated with letrozole $(2.5 \mathrm{mg} /$ day), it was concluded that letrozole may be of potential benefit for improving ovarian response to FSH in poor responders (Mitwally \& Casper 2002). Similarly, in a case-controlled study Garcia-Velasco et al. reported a significantly higher numbers of oocytes retrieved and implantation rates in letrozole-treated patients (GarciaVelasco et al. 2005). Several further studies have reported on the positive effect of letrozole in lowering the total does of FSH used (Mitwally \& Casper 2002, Goswami et al. 2004, Ozmen et al. 2009, Yarali et al. 2009, Mohsen \& El Din 2013, Lee et al. 2014), but the key IVF outcomes of number of oocyte retrieved, fertilization rates and pregnancy rates have not consistently been found to 
(1)

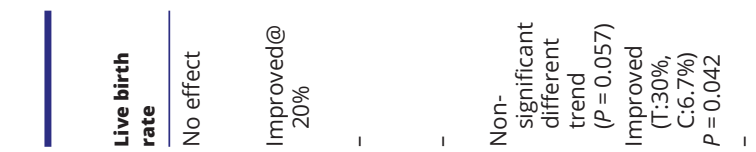

I

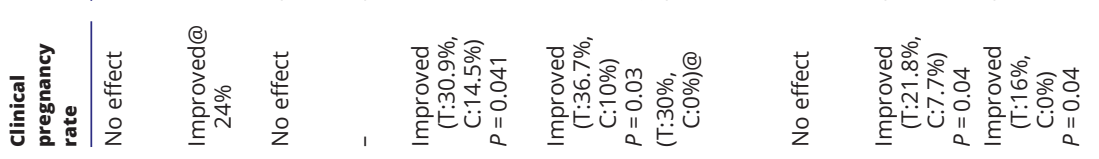

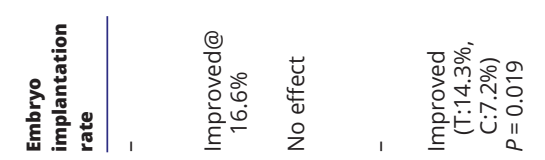

i

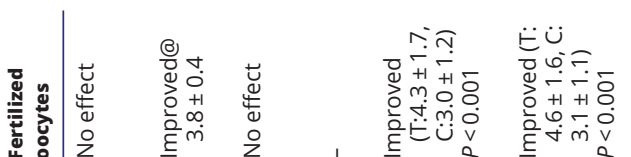

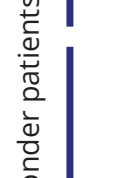

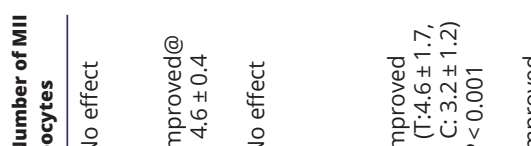

छ̛ंmv

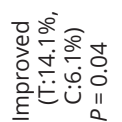

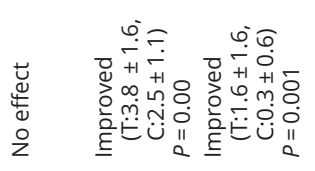

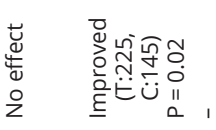

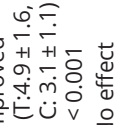

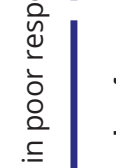

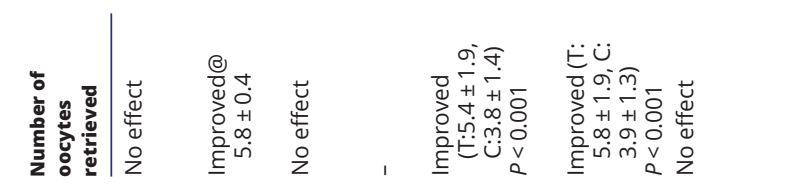

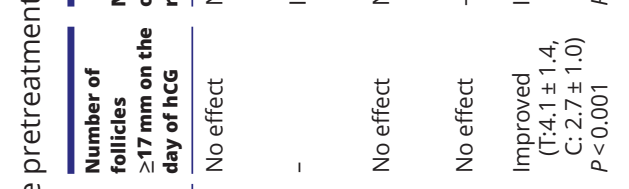

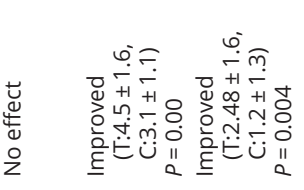

$\mid \frac{0}{\frac{0}{\sigma}}$

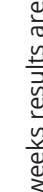

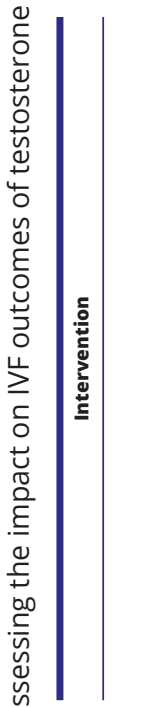

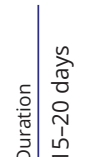

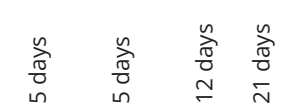

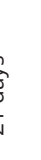

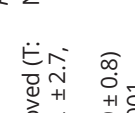

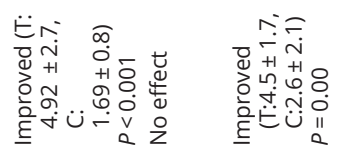

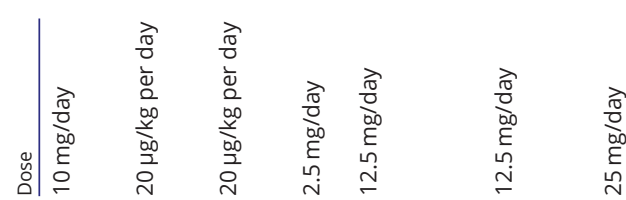

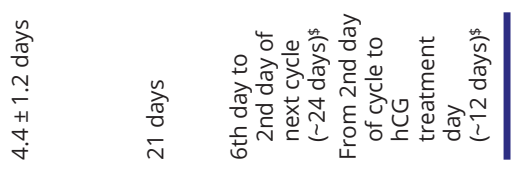

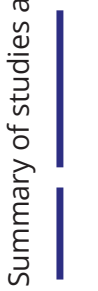

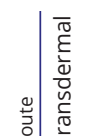

要

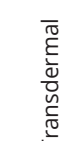

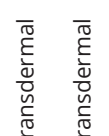

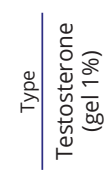

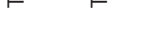

r.

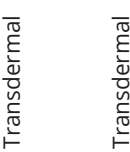

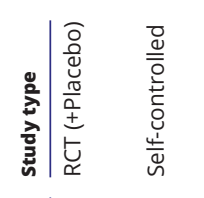

竞

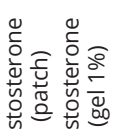

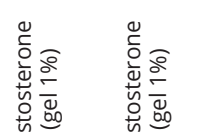

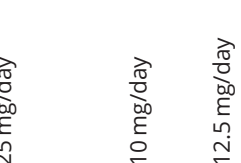

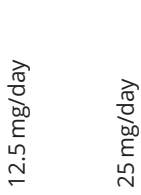

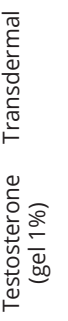

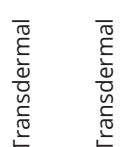

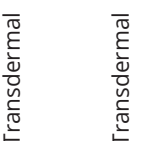

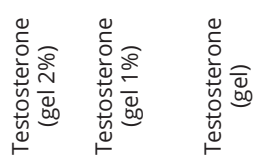

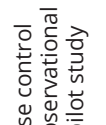

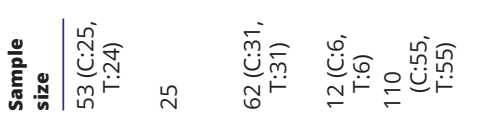

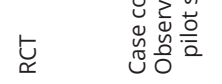

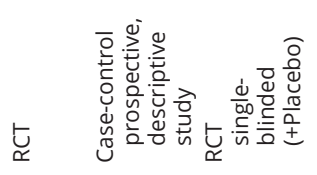

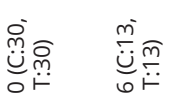

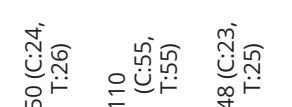

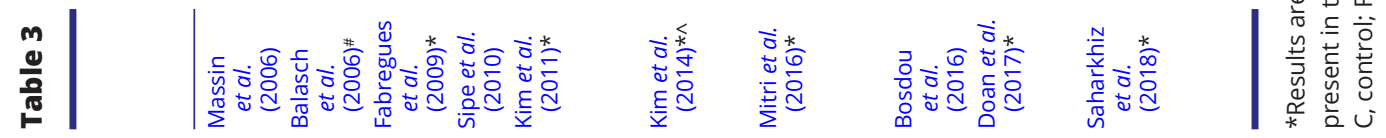

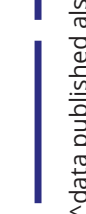


be significantly improved by the supplementation of poor responders with letrozole (Goswami et al. 2004, Schoolcraft et al. 2008, Ozmen et al. 2009, Yarali et al. 2009, Jovanovic et al. 2011, Mohsen \& El Din 2013, Lee et al. 2014, Ebrahimi et al. 2017). Furthermore, analysis of pooled data from several studies also fail to show a significant association with increased clinical pregnancy rates (Bosdou et al. 2012, Jeve \& Bhandari 2016, Kamath et al. 2017). Hence, at present, the incorporation of letrozole does not appear to be an effective way to manage poor responders, as overall, the findings are inconclusive and provide little evidence to support its use.

\section{Recombinant luteinizing hormone ( $r \mathrm{LH})$ /recombinant human chorionic gonadotrophin (rhCG)}

Based on the two-cell two-gonadotrophin hypothesis (Fig. 2), androgen production in the theca cells is stimulated by the presence of LH (Hillier et al. 1994), inferring that LH activity is crucial for maintaining adequate levels of intraovarian androgens during ovarian follicle development. It has also been reported that ovarian response and pregnancy outcome are related to LH levels in women undergoing assisted reproduction, with women receiving pituitary downregulation with gonadotrophinreleasing hormone (GnRH) agonists displaying a compromised pregnancy outcome (Westergaard et al. 2000, Humaidan et al. 2002). Hence, the use of $\mathrm{rLH} / \mathrm{rhCG}$ to mimic endogenous LH has been put forward as a potential strategy to manage poor responders.

In two randomized controlled studies published by Ferraretti et al. in 2004 and 2014, administration of rLH treatment was reported to significantly improve live birth rates in poor responders (Ferraretti et al. 2004, 2014). However, in another three controlled studies published on the use of rLH or rhCG in poor responders, no statistically significant beneficial effects were reported on the number of oocytes retrieved or pregnancy rates (Berkkanoglu et al. 2007, Ruvolo et al. 2007, Barrenetxea et al. 2008). Unfortunately all reported studies lack a placebo, and systematic review and meta-analysis of the limited available evidence have concluded that there are insufficient data to draw firm conclusions and support a beneficial effect of rLH or rhCG in poor responders (Bosdou et al. 2012, Jeve \& Bhandari 2016).

\section{Androgen or androgen-modulating agent combination therapies}

In a few cases, modified strategies combining androgens or androgen-modulating agents have also been trialed in
POR patients. A significant improvement in the number of oocytes retrieved and clinical pregnancy rates was reported in a study that used a combination therapy of DHEA for 12 weeks, transdermal testosterone for 4 weeks and growth hormone later in the luteal phase (Haydardedeoglu et al. 2015). Additionally, in another treatment strategy, called ANDRO-IVF, combining pre-treatment with transdermal testosterone, letrozole and hCG, it was reported that POR patients exhibited a significant increase in the number of oocytes retrieved and fertilization rates (Bercaire et al. 2018). However, it is noteworthy that neither study had a placebo control.

\section{Current implications and future directions from basic research on the clinical use of androgens or androgen-modulating agents in POR patients}

In summary, at present, further studies are required to confirm the efficacy of adjacent administration of androgens or androgen-modulating agents in poor responder cases. There is accumulating evidence from basic discovery research, clinical trials, meta-analysis and systematic reviews (including a Cochran review; Nagels et al. 2015) to support the use of androgen pre-treatment, in particular transdermal testosterone, in POR patients. However, conflicting results have been reported on the efficacy of these strategies. Reasons for these differential effects include study design flaws such as lack of placebo, small sample size, inconsistent inclusion criteria and ambiguous use of aromatizable androgens. Testosterone is a bioactive androgen that can bind directly to the AR, while DHEA is considered an inactive androgen precursor which has a very week affinity for the AR. Hence, for DHEA pre-treatment to elicit a physiological response, the correct enzyme machinery must be in place to convert this androgen precursor into one of the active androgens, testosterone or DHT. Following this logic, it could be proposed that the use of testosterone, rather than DHEA, would be of more benefit in the clinic.

The molecular mechanism(s) that mediate the proposed beneficial effects of androgen pre-treatment on IVF outcomes remain undefined. However, animal studies have clearly shown that androgens increase FSH receptor expression, and synergize with FSH to stimulate follicle growth and follicle responsiveness to FSH (Weil et al. 1999, Wang et al. 2001, Sen et al. 2014). In support of this synergistic interaction, DHEA supplementation was reported to significantly increase protein and mRNA 
FSH receptor expression in preovulatory granulosa cells collected from POR patients (Hu et al. 2017). Another potential mechanism by which androgen pre-treatment may mediate a beneficial effect is by maintaining follicle health. Androgens have been demonstrated to influence follicle atresia as systemic treatment with testosterone or DHT reduced follicle atresia in primate growing follicles (Vendola et al. 1998). On the other hand, a loss of androgen actions, as in ARKO models, leads to elevated levels of follicular atresia, evident by the presence of pyknotic granulosa cells and degenerate oocytes ( $\mathrm{Hu}$ et al. 2004, Shiina et al. 2006, Walters et al. 2007). Clinical evidence supporting this mechanism come from the findings from one study that compared to normal ovarian responders, POR patients supplemented with DHEA were reported to produce a greater number of top-quality embryos on day 3 and increased fertilization rates, and their cumulus cells displayed reduced DNA damage and expression of apoptosis-related genes (Lin et al. 2017). Similarly in another study, cumulus cells collected before and after DHEA treatment in women with POR displayed an increase in the ratio of $B C L 2$ (anti-apoptotic) to $B A X$ (pro-apoptotic) (Tsui et al. 2014). Moreover, in the same study, genes involved in extracellular matrix formation were upregulated in cumulus cells, indicating that DHEA treatment may improve oocyte-cumulus cell process during maturation (Tsui et al. 2014).

In spite of the abundant reports of beneficial effects, numerous reviews on this subject have reiterated that at present caution should still be taken when interpreting results as the majority of studies lack placebo controls, have small sample sizes and display major heterogeneity between studies in terms of dose and duration of androgen/androgen-modulating agent treatment. Hence, further RCTs with rigorous methodology and inclusion criteria are urgently needed. At present one such trial, called the Testosterone TRANSdermal Gel for Poor Ovarian Responders Trial (T-TRANSPORT; NCT02418572; Polyzos et al. 2018) is currently underway with an estimated completion date of June 2019. This trial has aimed to undertake a double-blind placebo-control trial in five IVF centers, in at least four countries, with a large sample size (400 women) to assess effectively the impact of transdermal testosterone $(5.5 \mathrm{mg} /$ day $)$ for $\sim 65$ days with fixed stimulation protocols (Trial details available at https://clinicaltrials.gov/ct2/show/NCT02418572). While we await the outcome from studies such as this with great interest, and despite indications of promising beneficial effects of increasing androgen exposure prior to an IVF cycle, at present androgen pre-treatments continue to be widely used in IVF centers around the world without convincing evidence or defined molecular mechanisms to support their continued use.

\section{Defining polycystic ovary syndrome (PCOS) and evidence to support a role for androgen-driven mechanisms in the development of PCOS}

\section{Characteristics and diagnosis of PCOS}

PCOS has a significant prevalence worldwide, with reports of up to $20 \%$ of women of reproductive age being affected by the condition, which poses a high economic health burden (March et al. 2010, Dumesic et al. 2015, Bozdag et al. 2016, Skiba et al. 2018). PCOS women suffer from a wide range of ill-health traits, which include endocrine, reproductive, metabolic and psychological features. Polycystic ovaries classically exhibit aberrant follicle maturation which leads to ovulatory dysfunction and is associated with reduced fertility (Dumesic et al. 2015). If pregnancy is achieved, PCOS patients have a greater risk of pregnancy complications, such as gestational diabetes, hypertensive disorders and premature delivery (Boyle \& Teede 2016). Other key traits of PCOS include hormonal disturbances with hyperandrogenism and $\mathrm{LH}$ hypersecretion frequently observed in PCOS women (Dumesic et al. 2015). PCOS also has a substantial metabolic impact as it is strongly associated with obesity, metabolic syndrome, hyperinsulinemia, insulin resistance, dyslipidemia, hepatic steatosis and an increased risk of developing type 2 diabetes and cardiovascular disease (Shorakae et al. 2014, Dumesic et al. 2015, Moran et al. 2015). Moreover, PCOS is associated with psychosocial issues with the prevalence of depression and anxiety reported to be higher in PCOS women (Dumesic et al. 2015).

Three different diagnostic criteria for the diagnosis of PCOS have been used including the National Institutes of Health (NIH) (Zawadzki \& Da 1992), Rotterdam (Rotterdam 2004) and Androgen Excess and PCOS (AE-PCOS) criteria (Azziz et al. 2006, 2009). In 2018, the international evidence-based guidelines for the assessment and management of PCOS endorsed the most widely used criteria, the Rotterdam diagnostic criteria, which states that a women must present two out of the following three PCOS features for a diagnosis: clinical and/or biochemical androgen excess, oligo-anovulation or anovulation and polycystic ovary morphology (PCOM) 
on ultrasound (Rotterdam 2004, Teede et al. 2018) (Fig. 3). Unfortunately, despite PCOS being a highly prevalent condition with major health and economic impacts, a cure for PCOS is yet to be identified. This is because the origins and underlying mechanisms driving PCOS remain unclear, and consequently, no drug has been specifically approved for the indication of PCOS (Escobar-Morreale 2018). Due to this, the current medical management of women with PCOS remains suboptimal as it focuses only on treatment of the symptoms rather than the underlying mechanisms.

\section{Clinical evidence supporting a role for androgens in driving the development of PCOS}

\section{Correlation between androgen levels and the observation of PCOS traits}

Androgen excess is a key trait in the majority ( $60 \%)$ of women with PCOS, and the most frequent common feature, as hyperandrogenism is a diagnostic criteria in three out of the four PCOS phenotypes (A-D) endorsed by the 2018 international evidence-based guidelines (Livadas et al. 2014, Teede et al. 2018). Interestingly, the presence of elevated androgen levels observed in congenital adrenal hyperplasia patients (Lucis et al. 1966, Hague et al. 1990) and female-to-male transsexuals treated with testosterone (Futterweit \& Deligdisch 1986, Spinder et al. 1989, De Roo et al. 2017) are reported to cause the appearance of polycystic ovarian morphology (PCOM), similar to that observed in women with PCOS, with enlarged ovaries that exhibit multiple cysts and theca interstitial hyperplasia. Serum levels of testosterone, A4 and DHEAS, and the enzyme required to transform pro-androgens to bioactive

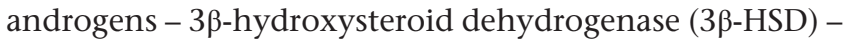
have all been reported to be elevated in hyperandrogenic PCOS women (Keefe et al. 2014, Palomba et al. 2014,
O'Reilly et al. 2017). In addition, recently, it has been reported that 11-oxygenated androgens, including the potent androgen 11-ketotestosterone (11KT), represent the majority of circulating androgens in women with PCOS, and there is a close correlation of a number of 11-oxygenated steroids with hyperinsulinemia, highlighting a potential important role for these steroids as biomarkers of metabolic risk (O'Reilly et al. 2017). Furthermore, human theca interna cells excised from ovaries of PCOS women display elevated levels of androgen secretion which persists over long term in vitro, inferring that PCOS ovaries are a site of endogenous excess androgen production (Nelson et al. 1999). Observational studies have also reported that androgen excess is positively correlated with several PCOS characteristics, including increased intra-abdominal fat mass, triglyceride levels, LH/FSH ratio and insulin resistance, but decreased high-density lipoprotein levels (Daan et al. 2015, Dumesic et al. 2016, Li et al. 2016, Couto Alves et al. 2017). Taken together, these findings provide substantial clinical evidence pointing toward an important role for androgenic actions in the development and progression of PCOS.

\section{Pharmacological targeting of androgen excess effects in patients with PCOS}

No universal treatment for PCOS is currently available and therefore treatments are based on an individual patient and symptom basis. Hirsutism, acne and alopecia are all manifestations of androgen excess observed in PCOS patients. In women not attempting to conceive, drugs with anti-androgenic properties, including the oral contraceptive pill containing progestin with low or antiandrogen activity and/or antiandrogens, have been used for treating PCOS symptoms.

\begin{tabular}{|c|c|c|c|c|}
\cline { 2 - 5 } \multicolumn{1}{c|}{} & $\begin{array}{c}\text { HA + OA + PCOM } \\
\text { (Phenotype A) }\end{array}$ & $\begin{array}{c}\text { HA + OA } \\
\text { (Phenotype B) }\end{array}$ & $\begin{array}{c}\text { HA+ PCOM } \\
\text { (Phenotype C) }\end{array}$ & $\begin{array}{c}\text { OA + PCOM } \\
\text { (Phenotype D) }\end{array}$ \\
\hline Rotterdam* & $\checkmark$ & $\checkmark$ & $\checkmark$ & $\checkmark$ \\
AE-PCOS & $\checkmark$ & $\checkmark$ & $\checkmark$ & \\
NIH & $\checkmark$ & $\checkmark$ & & \\
\hline
\end{tabular}

\section{Figure 3}

Combinations of clinical observations used to diagnose PCOS according to the three different PCOS diagnostic criteria (Rotterdam, AE-PCOS, NIH) and the four different PCOS phenotypes (A-D). $\checkmark$, presence of clinical observations. *Rotterdam is the recommended diagnostic criterion which is endorsed by the 2018 international evidence-based guidelines for the assessment and management of PCOS (Teede et al. 2018). HA, hyperandrogenism (clinical: acne, alopecia (Ludwig visual score), and hirsutism (Ferriman-Gallwey score $\geq 4-6$ ) and/or biochemical: calculated free testosterone, free androgen index or calculated bioavailable testosterone using liquid chromatography-mass spectrometry (LCMS) and extraction/chromatography immunoassays). OA, oligo- or anovulation ( $<21$ or $>35$ days cycles or $<8$ cycles per year 3 years post menarche to perimenopause). PCOM, polycystic ovarian morphology ( $\geq 20$ follicles/ovary and/or an ovarian volume $\geq 10 \mathrm{~mL}$ on either ovary using endovaginal ultrasound transducer with a frequency $\geq 8 \mathrm{mHz}$; and/or ovarian volume $\geq 10 \mathrm{~mL}$ using older technology or transabdominal ultrasound). 
Administration of the oral contraceptive pill inhibits the midcycle LH surge by suppressing GnRH secretion from the hypothalamus and gonadotrophin secretion from the pituitary. In addition to the primary role of providing contraception, the suppression of gonadotrophin secretion in turn also reduces ovarian steroidogenesis, and hence, leads to a reduction in circulating androgen levels (Zimmerman et al. 2014). Furthermore, oral contraceptive pill treatment causes an estrogen dose-dependent increase in sex hormone-binding globulin (SHBG) from the liver, thereby further reducing the availability of active androgens (Zimmerman et al. 2014). These antiandrogenic qualities make the oral contraceptive pill an effective mainstay pharmacological therapy for treating the symptoms of menstrual irregularity, hirsutism, acne and androgenic alopecia in patients with PCOS not wishing to conceive (Yildiz 2008, Legro et al. 2013, Conway et al. 2014, Mendoza et al. 2014). In addition, recent evidence on third-generation combined oral contraceptive pills that contain an anti-androgenic compound has suggested that they may have beneficial effects on metabolic phenotypes of PCOS, with improved lipid profiles and adipokine secretion (Legro et al. 2013).

Spironolactone and cyproterone acetate are both steroidal AR blockers that compete with the bioactive androgens testosterone and DHT for the AR ligandbinding domain. Numerous studies have reported that the treatment of PCOS patients with either AR blocker is an effective way to significantly decrease hirsutism and acne (Conway et al. 2014, Escobar-Morreale 2018). Furthermore, spironolactone therapy in women with PCOS has been associated with a significant improvement in metabolic phenotype (Zulian et al. 2005). However this is not the case in all studies, with either no effect observed (Diri et al. 2016) or an adverse effect reported on serum lipoprotein levels (Nakhjavani et al. 2009).

Flutamide is a synthetic nonsteroidal antiandrogen that is a competitive antagonist of the AR. Flutamide has been reported to exert a beneficial effect in women with PCOS, by decreasing the degree of hirsutism and acne observed (Venturoli et al. 1999, Moghetti et al. 2000, Calaf et al. 2007). Treatment of PCOS patients with flutamide restores menstrual regularity and ovulation (De Leo et al. 1998, Paradisi et al. 2013) and ameliorates the impaired sensitivity of the GnRH pulse generator to feedback inhibition by E2 and progesterone (Eagleson et al. 2000). Interestingly, when flutamide was used in combination with a hypocaloric diet in overweight-obese PCOS women, it was reported to not only improve hirsutism but also have beneficial effects on other reproductive and metabolic disturbances associated with PCOS, including menstrual pattern, glucose-stimulated glucose levels, insulin sensitivity and low-density lipoprotein and cholesterol levels (Gambineri et al. 2006). Moreover, treatment of obese and lean PCOS women with flutamide improves lipid profile independent of changes in weight, with treatment associated with a significant decrease in low-density lipoproteins (LDL) to high-density lipoproteins (HDL) ratio, total cholesterol, LDL and triglycerides (Diamanti-Kandarakis et al. 1998).

Finasteride, a 5-alpha reductase inhibitor, has been described to be effective for the treatment of the hirsutism in patients with PCOS (Lakryc et al. 2003, Tartagni et al. 2014). Moreover, in a double-blind randomized study, hyperandrogenic anovulatory PCOS women who previously did not respond to stimulation with gonadotrophin, were found to display improved ovulation rates after the addition of finasteride during ovarian stimulation (Tartagni et al. 2010).

Collectively findings from the use of anti-androgenic drugs in PCOS patients either alone or in combination have shown that targeted suppression of androgen excess, and thus, androgenic actions, has a positive impact with improvements observed in several features of PCOS. As androgens mediate their actions via the AR, these findings provided support for a link between androgen excess and the development of a wide range of PCOS traits. However, importantly these treatments are not curative, and such pharmacological treatments are only an option for PCOS women not desiring a pregnancy as antiandrogens should only be used with concomitant contraception to avoid masculinization of a female fetus in the event of an unplanned pregnancy. Furthermore, there is evidence to support that antiandrogens have unacceptable hepatotoxicity (Conway et al. 2014), which outweighs their benefits in use for non-lethal disorders, such as PCOS. Hence, while systemic androgen blockade is a logical approach for treating PCOS, a more targeted pharmacological approach is needed, but this requires an in-depth knowledge of the physiological mechanisms underpinning its evolution.

\section{Evidence from hyperandrogenized preclinical animal PCOS models supporting a role for androgens in driving the development of PCOS}

Fully controlled studies into the fundamental biological mechanisms underlying the development of PCOS are not possible in humans as clinical studies are limited by ethical and logistical constraints. Therefore, preclinical PCOS 
animal models that mimic PCOS-like traits are essential in providing insights into the specific mechanisms underpinning the pathogenesis of PCOS. Animal models for the study of PCOS have been developed using a variety of methods, from treatment with androgens, estrogens and antiprogestins to genetic manipulation and chronic exposure to light (Walters et al. 2012a, 2018a, Walters 2015). However, the most insightful information on the underlying mechanisms involved in the origins of PCOS have come from preclinical PCOS animal models generated by inducing hyperandrogenism (Walters et al. 2018a). Androgen excess-induced PCOS traits have been generated in female rodents, sheep and rhesus macaque monkeys by prenatal or postnatal injection or subcutaneous implants containing the pro-androgen DHEA, androgens testosterone or DHT or the aromatase inhibitor letrozole (Walters et al. 2012a, Abbott et al. 2013, Padmanabhan \& Veiga-Lopez 2013) (Fig. 4). Collectively, these PCOS animal models provide strong evidence that hyperandrogenism is a major driver in PCOS pathogenesis as they consistently replicate a wide range of PCOS traits observed in humans.

Two rodent PCOS models that have been reported to closely mimic human key endocrine, reproductive and metabolic PCOS traits are the models generated by prenatal or early postnatal exposure to DHT. The prenatal DHT-induced PCOS mouse model exhibits the clinical endocrine and reproductive PCOS features of hyperandrogenism, LH hypersecretion, irregular cycles, reduced fertility and ovulatory dysfunction (Sullivan \& Moenter 2004, Moore et al. 2013). While this model has been reported to not have a strong metabolic PCOS phenotype and may be most representative of the lean PCOS phenotype, it has been reported that adipocyte hypertrophy and impaired glucose tolerance are still present, inferring that metabolic function is still aberrant (Roland et al. 2010, Caldwell et al. 2014). Early postnatal DHT exposure induces a robust mouse PCOS model with a wide range of PCOS traits including irregular cycles, ovulatory dysfunction, PCOM, adiposity, adipocyte hypertrophy, dyslipidemia, hepatic steatosis and altered glucose and insulin homeostasis (Caldwell et al. 2014, Bertoldo et al. 2019). In sheep and nonhuman primate PCOS models, prenatal exposure to testosterone generates the closest simulation to the clinical features of PCOS, with both models also displaying a breadth of endocrine, reproductive and metabolic PCOS traits, including irregular cycles, oligo- or anovulation, PCOM, LH hypersecretion, lipid abnormalities and insulin resistance (Padmanabhan \& Veiga-Lopez 2013, Abbott et al. 2016).
Further evidence to support androgens as key drivers in the etiology of PCOS come from the observations that treatment of PCOS animal models with AR antagonists prevents/or rescues the development of some PCOS traits. Ovulatory dysfunction is present in the prenatally androgenized PCOS sheep model, but co-treatment with the AR antagonist flutamide restores LH surges (Padmanabhan et al. 2015). In a mouse PCOS model, androgen excess leads to irregular cycles and a disruption within the arcuate nucleus of the hypothalamus of neuronal networks involved in mediating progesteronesensitive GABAergic input to GnRH neurons (Sullivan \& Moenter 2004, Moore et al. 2015). However, treatment of adult prenatally androgenized female mice with flutamide ameliorated the disrupted estrous cycling and altered GABAergic drive to GnRH neurons (Sullivan \& Moenter 2004). Metabolic dysfunction associated with PCOS has also been speculated to be, at least in part, regulated by androgen-mediated mechanisms impacting on specific hypothalamic circuitry important in energy balance and metabolism. Prenatally androgenized sheep exhibit alterations in agouti-related peptide (AgRP) neurons (known to be involved in regulating energy homeostasis and glucose-insulin metabolism), but these changes are blocked by prenatal co-treatment with flutamide (Sheppard et al. 2011). Collectively, these intervention studies provide evidence that androgen actions mediated via the AR significantly contribute to the development of PCOS traits.

\section{Use of ARKO mouse models to decipher key target sites involved in the pathogenesis of PCOS}

With the large body of evidence from observational clinical studies and the generation and characterization of androgen excess-induced PCOS animal models supporting a role for hyperandrogenism in the developmental origins of PCOS, recent research has been focusing on identifying the site of these actions and the mechanisms involved (Fig. 5). As direct androgen actions mediate their actions via the AR, several recent studies have incorporated the use of ARKO mouse models as a tool to unravel the role of androgens in the development of PCOS. PCOS could not be induced in homozygous global ARKO mice by exposure of female mice to androgen excess (Caldwell et al. 2015, 2017), providing strong evidence of a requirement for a functional AR in the pathogenesis of experimental PCOS. It has been proposed that androgen excess acting via the AR at various locations throughout the body, including the 


\begin{tabular}{lcccc} 
Clinical features of PCOS & $\begin{array}{c}\text { Women } \\
\text { with } \\
\text { PCOS }\end{array}$ & $\begin{array}{c}\text { PCOS } \\
\text { Rodent } \\
\text { Models }\end{array}$ & $\begin{array}{c}\text { PCOep } \\
\text { Models }\end{array}$ & $\begin{array}{c}\text { PCOS } \\
\text { Models }\end{array}$ \\
\hline Irregular cycles/ acyclicity & $\checkmark$ & $\checkmark$ & $\checkmark$ & $\checkmark$ \\
Oligo- or anovulation & $\checkmark$ & $\checkmark$ & $\checkmark$ & $\checkmark$ \\
Polycystic ovarian morphology & $\checkmark$ & $\checkmark$ & $\checkmark$ & $\checkmark$ \\
Hyperandrogenism & $\checkmark$ & $\checkmark$ & $\checkmark$ & $\checkmark$ \\
LH hypersecretion & $\checkmark$ & $\checkmark$ & $\checkmark$ & $\checkmark$ \\
Aberrant follicle dynamics & $\checkmark$ & $\checkmark$ & $\checkmark$ & $\checkmark$ \\
Increased adiposity & $\checkmark$ & $\checkmark$ & $\mathbf{X}$ & $\checkmark$ \\
Dyslipidaemia & $\checkmark$ & $\checkmark$ & $\checkmark$ & $\checkmark$ \\
Insulin resistance & $\checkmark$ & $\checkmark$ & $\checkmark$ & -- \\
Non-alcoholic fatty liver & $\checkmark$ & $\checkmark$ & & $\checkmark$ \\
\hline
\end{tabular}

\section{Figure 4}

Presence of clinical PCOS traits in

hyperandrogenic animal models. Prenatal and/or postnatal treatment of testosterone or DHT in rodents (mice and rats), sheep and nonhuman primates is an effective way to replicate most endocrine, reproductive and metabolic features of human PCOS, hence providing valuable preclinical animal models for basic discovery research. $\boldsymbol{\checkmark}$, presence of PCOS phenotype. $\mathbf{X}$, absence of PCOS phenotype. $\mathbf{\Delta}$, non-significant tendency for increased cholesterol, triglycerides, high-density lipoprotein (HDL) and low-density lipoprotein (LDL). -, not reported. hypothalamus, ovary, skeletal muscle or adipocyte cells, are involved in the origins of PCOS.

The contribution and importance of intra- versus extra-ovarian mechanisms in the pathogenesis of PCOS has been a key question in understanding the processes involved in the development of PCOS. Recent studies combining PCOS mouse models and global and cell-specific ARKO mouse models have made significant advances in our understanding of the likely mechanisms involved. Induction of PCOS traits by androgen excess in control mice and ovariectomized control mice with transplanted ARKO ovaries (i.e. only the ovaries have non-functional AR signaling) leads to the development of PCOS traits of disrupted cycles. In contrast, when PCOS was induced by excess androgen exposure in ovariectomized global ARKO mice with transplanted control ovaries (i.e. only ovaries have functional AR signaling), normal cyclicity was retained (Caldwell et al. 2017), inferring that extra-ovarian mechanism are the major mediators in the development of PCOS. To tease out the key sites of these AR actions, several studies have induced PCOS in mice with a loss of AR function only in the brain, granulosa cells or theca cells. Findings from these studies have pinpointed the brain as a key site at the core of PCOS pathogenesis, as silencing of $\mathrm{AR}$ actions in the brain protected female mice from developing the majority of reproductive and metabolic

\section{Androgen excess}

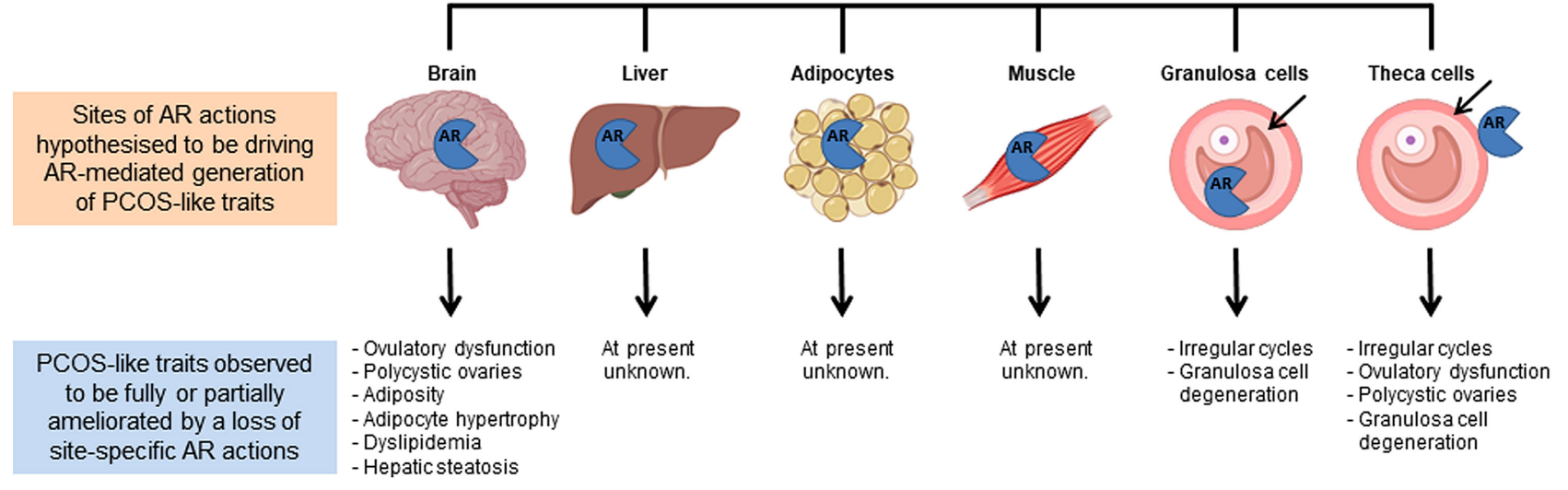

Figure 5

Schematic diagram of proposed site-specific androgen receptor (AR)-mediated actions contributing to the induction of PCOS traits. Currently, as the origins of PCOS remains unknown, mechanism-based treatments are not feasible, and management relies on the treatment of symptoms only. Here we illustrate the proposed sites of AR-mediated actions involved in generating PCOS traits. This knowledge serves as a guide for future basic discovery research by highlighting target sites to focus on unraveling the defective mechanisms causing the development of PCOS traits. Identification of these underlying altered mechanisms involved in the pathogenesis of PCOS would allow development of new targeted, evidence-based interventions for PCOS. 
PCOS traits, including ovulatory dysfunction, increased adiposity, dyslipidemia and pronounced adipocyte hypertrophy and hepatic steatosis (Abbott 2017, Caldwell et al. 2017). In comparison to the brain-specific ARKO mouse, like controls, female mice with a loss of function only in the granulosa cells still displayed the majority of PCOS characteristics with only a full protection against an increase in granulosa cell degeneration in antral follicles observed (Caldwell et al. 2017). In addition, only a partial prevention of the development of acyclicity, dysfunctional ovulation and infertility were observed in a hyperandrogenic PCOS mouse model with an inactivation of AR signaling only in the theca cells (Ma et al. 2017). Collectively, these results provide strong evidence that while ovarian AR actions may contribute to the development of reproductive features in PCOS, the brain is the prominent site and neuroendocrine androgendriven molecular mechanisms are the key mediators in the developmental origins of PCOS traits.

\section{Current implications and future directions from basic research on the development of novel PCOS treatments targeting androgen-driven mechanisms}

Substantial evidence supports a role for androgen excess mediating its actions via the AR in the origin of PCOS, but systemic treatment with present generations of antiandrogens is not a viable option due to unacceptable liver toxicity that preclude their use for non-lethal chronic disorders. Therefore, recent research has been aimed at trying to identify more targeted ways by which pharmacological strategies may be able to suppress excess androgenic effects in women with PCOS.

One such approach would be to target AR-driven neuroendocrine pathways. A specific loss of AR signaling in the brain protects hyperandrogenized PCOS mice against the development of PCOS traits, pinpointing the brain as a key site involved in experimental PCOS pathogenesis (Caldwell et al. 2017). An increase in LH-toFSH ratio and LH pulse frequency are frequently observed in PCOS patients (Dumesic et al. 2015) and also in rat (Wu et al. 2010), mouse (Moore et al. 2013, 2015), sheep (Sarma et al. 2005) and primate (Abbott et al. 2018) PCOS models. The activity of GnRH neurons, which regulate gonadotrophin secretion, is highly dependent upon homeostatic feedback and gonadal steroid hormone signaling in the brain. However, GnRH neurons do not express AR (Huang \& Harlan 1993). Instead, AR is expressed within intermediary neuronal networks that lie upstream of the GnRH neurons, allowing an indirect pathway for AR-mediated actions. One such neuronal network that expresses AR is the kisspeptin-neurokinin $\mathrm{B}$ (NKB)- dynorphin 'KNDy' system within the arcuate nucleus which plays a pivotal role in the regulation of GnRH secretion (Navarro et al. 2009, Smith 2013, Skorupskaite et al. 2014). AR-mediated signaling plays a role in regulating the KNDy system (Walters et al. 2018b) and rodent and sheep hyperandrogenized PCOS animal models display changes in KNDy expression and circuitry (Brown et al. 2012, Cernea et al. 2015, Kauffman et al. 2015, Osuka et al. 2017). These findings imply that the KNDy system may be an attractive therapeutic target to modulate AR-driven neuroendocrine activity in PCOS patients. Indeed, increased kisspeptin has been reported in several populations of PCOS patients (Albalawi et al. 2018, Katulski et al. 2018, Umayal et al. 2019). Of note, not all populations of women with PCOS exhibit changes in kisspeptin levels (Daghestani 2018, Katulski et al. 2018), inferring alterations in the KNDy system may be related to differences in PCOS phenotype or severity. Recent clinical studies also provide support for modulation of the KNDy system as a potential new target for the development of treatment for PCOS. Treatment of women with a NK3R antagonist decreases ovarian hormone levels (Fraser et al. 2016), while more specifically, treatment of PCOS patients with a NKB receptor antagonist reduced LH pulse frequency and LH and testosterone concentrations, which are characteristics of PCOS (George et al. 2016).

Moreover, the finding that a specific loss of AR signaling in the brain protects hyperandrogenized PCOS mice against the development of key metabolic PCOS traits, including increased body weight and visceral fat, dyslipidemia and pronounced adipocyte hypertrophy and hepatic steatosis, indicates that some aspects of metabolic dysfunction observed in PCOS patients may be mediated via AR-regulated central mechanisms (Caldwell et al. 2017). In fact, there is evidence to suggest that an androgenbrain-adipocyte axis may play a role in the etiology of PCOS-associated metabolic dysfunction. The adipokine leptin, which plays an important role in regulating energy homeostasis, has reduced impact on energy expenditure in a mouse model of androgen excess. This coincides with a decrease in sympathetic outflow to brown adipose tissue (BAT) (Nohara et al. 2014). Proopiomelanocortin (POMC) and neuropeptide Y/agouti-related peptide (NPY/AgRP) neurons are well-known targets of leptin (Villanueva \& Myers 2008) and have been reported to be influenced by androgen excess. Pomc mRNA and fiber projections 
are reduced in androgenized female mice (Nohara et al. 2014), while in the ewe prenatal androgen excess leads to increased NPY/AgRP cell number and fiber projections (Sheppard et al. 2011). In addition, treatment with the AR antagonist flutamide blocks the observed changes in NPY/AgRP neurons in androgenized sheep (Sheppard et al. 2011) and also improves lipid profiles in women with PCOS, independent of weight change, glucose metabolism and insulin sensitivity (Diamanti-Kandarakis et al. 1998). Collectively, these results are supportive of a central role for androgens in mediating PCOS-related metabolic dysregulation and support further research in determining the precise mechanisms involved.

AR-driven pathways within adipose tissue may also be important to investigate in the development of new strategies to treat PCOS. Studies have shown intra-abdominal fat mass is significantly increased in women with PCOS and that this increase is positively correlated with serum androgen levels (Dumesic et al. 2016). Hyperandrogenized rodent, sheep and primate PCOS models exhibit changes in adipocyte morphology and/or function (Keller et al. 2014, Cardoso et al. 2016, Caldwell et al. 2017). Interestingly, in the ewe model, observed alterations in adipocyte morphology are present before insulin insensitivity is evident, inferring that defective adipocyte function may precede the onset of metabolic dysfunction. Hence, research identifying the mechanisms underpinning these alterations may provide targets for the development of interventions aimed at treating PCOS from an early stage of its development and potentially blocking its progression. A potential androgen excess AR-driven defect within adipocyte cells involved in generating the PCOS phenotype may be the ability of adipocytes to produce adequate levels of the adipokines. At present, understanding the precise role the adipokine adiponectin plays in the development of PCOS is of particular interest. Adiponectin is important in glucose and lipid metabolism and has been observed to be decreased in women with PCOS (Manneras-Holm et al. 2011) and several PCOS mouse models (Benrick et al. 2017, Caldwell et al. 2017, Singh et al. 2017). Transplantation of BAT from control healthy rats into hyperandrogenic PCOS female rats enhances their BAT activity, increases serum adiponectin levels and ameliorates several key PCOS traits including irregular cycles and insulin resistance (Yuan et al. 2016). This study also revealed that exogenous adiponectin administration recapitulated the beneficial effects from BAT transplantation (Yuan et al. 2016), which was also confirmed in another hyperandrogenized mouse model of PCOS (Singh et al. 2017). Moreover, the findings that transgenic mice that overexpress adiponectin are protected from the induction of androgen excess metabolic PCOS traits, while mice that lack adiponectin display exaggerated or comparable PCOS features to the classic hyperandrogenized PCOS mouse model, highlights that modulation of adipokines, such as adiponectin, may provide a promising novel therapeutic strategy for the management of PCOS (Benrick et al. 2017). However, an understanding of the downstream mechanisms influenced by such factors is required. In addition while adipocyte AR actions appear to be important, the findings that altered glucose homeostasis in conjunction with hepatic steatosis but not insulin resistance has been observed in a DHT-induced mouse model of PCOS (Caldwell et al. 2017), suggests that AR actions within the hepatocyte, and potentially the muscle, may also play a role in the development of PCOS and warrant future investigation.

Less site-specific targeted approaches aimed at reducing androgen excess have also been put forward from preclinical research, with some directly translated into clinical trials. Dietary medium-chain fatty acid (decanoic acid) reduces androgen biosynthesis in vitro by modulating the steroidogenic enzyme HSD3B2, implying it may be a novel way to reduce androgen excess. In support of this, administration of decanoic acid to a rat PCOS model is reported to restore cyclicity and reduce testosterone and fasting insulin levels (Lee et al. 2016). Decanoic acid can be attained via dietary supplementation with mediumchain triglyceride oil, which has been shown to reduce body weight and total body fat in healthy adults (Mumme \& Stonehouse 2015), inferring this may be a useful therapy in tackling obesity which is often displayed in women with PCOS. Similarly, in vitro (Marti et al. 2017) and in vivo (Ergenoglu et al. 2015) studies have revealed that resveratrol, a polyphenol found in several plant species, inhibits androgen production by lowering CYP17 and CYP21 expression and activity and is effective in the treatment of some ovarian PCOS features observed in a rat PCOS model. A following clinical trial reported that PCOS patients treated with resveratrol exhibited a decrease in total testosterone and fasting insulin levels and an increase in Insulin Sensitivity Index (Banaszewska et al. 2016).

\section{Conclusion}

Results from clinical and animal studies have provided valuable congruent insight on the role of androgenic actions in regulating female reproduction and the 
mechanisms underpinning the development of PCOS. Discovery research has demonstrated that the correct balance in androgenic actions optimizes ovarian follicle development and female fertility. While clinical studies indicate that the use of androgen pre-treatment prior to an IVF cycle has a promising beneficial impact on IVF outcomes. Research using PCOS animal models has significantly advanced our understanding of the pathogenesis of PCOS, and the value of this knowledge is clearly highlighted by recent publications reporting on the evaluation of potential new treatments for PCOS that have been directly translated from preclinical studies. By continuing to combine results from clinical observations and basic discovery research, the precise androgenic mechanisms regulating ovarian function and the development of PCOS will be identified. This will open-up new avenues on how in the future we may achieve the development of evidence-based interventions that enhance ovarian response in POR patients and ameliorate symptoms in women with PCOS.

\section{Declaration of interest}

The authors declare that there is no conflict of interest that could be perceived as prejudicing the impartiality of this review.

\section{Funding}

Work carried out by $\operatorname{Dr} \mathrm{K}$ A Walters and colleagues was supported by a National Health and Medical Research Council project grant (APP1022648).

\section{Author contribution statement}

K A W, V R P, A A and D J H wrote paper and created figures.

\section{References}

Abbott DH 2017 Neuronal androgen receptor: molecular gateway to polycystic ovary syndrome? PNAS 114 4045-4047. (https://doi. $\operatorname{org} / 10.1073 /$ pnas.1703436114)

Abbott DH, Nicol LE, Levine JE, Xu N, Goodarzi MO \& Dumesic DA 2013 Nonhuman primate models of polycystic ovary syndrome. Molecular and Cellular Endocrinology 373 21-28. (https://doi.org/10.1016/j. mce.2013.01.013)

Abbott DH, Levine JE \& Dumesic DA 2016 Translational insight into polycystic ovary syndrome (PCOS) from female monkeys with PCOSlike traits. Current Pharmaceutical Design 22 5625-5633. (https://doi. org/10.2174/1381612822666160715133437)

Abbott DH, Vepraskas SH, Horton TH, Terasawa E \& Levine JE 2018 Accelerated episodic luteinizing hormone release accompanies blunted progesterone regulation in PCOS-like female rhesus monkeys (Macaca mulatta) exposed to testosterone during earlyto-mid gestation. Neuroendocrinology 107 133-146. (https://doi. org/10.1159/000490570)
Al-Turki HA 2018 Dehydroepiandrosterone supplementation in women undergoing assisted reproductive technology with poor ovarian response. A prospective case-control study. Journal of International Medical Research 46 143-149. (https://doi. org/10.1177/0300060517720005)

Albalawi FS, Daghestani MH, Daghestani MH, Eldali A \& Warsy AS 2018 rs4889 polymorphism in KISS1 gene, its effect on polycystic ovary syndrome development and anthropometric and hormonal parameters in Saudi women. Journal of Biomedical Science 2550. (https://doi.org/10.1186/s12929-018-0452-2)

Artini PG, Simi G, Ruggiero M, Pinelli S, Di Berardino OM, Papini F, Papini S, Monteleone P \& Cela V 2012 DHEA supplementation improves follicular microenviroment in poor responder patients. Gynecological Endocrinology 28 669-673. (https://doi.org/10.3109/0951 3590.2012.705386)

Azziz R, Carmina E, Dewailly D, Diamanti-Kandarakis E, EscobarMorreale HF, Futterweit W, Janssen OE, Legro RS, Norman RJ, Taylor AE, et al. 2006 Positions statement: Criteria for defining polycystic ovary syndrome as a predominantly hyperandrogenic syndrome: an androgen excess society guideline. Journal of Clinical Endocrinology and Metabolism 91 4237-4245. (https://doi.org/10.1210/ jc.2006-0178)

Azziz R, Carmina E, Dewailly D, Diamanti-Kandarakis E, EscobarMorreale HF, Futterweit W, Janssen OE, Legro RS, Norman RJ Taylor AE, et al. 2009 The androgen excess and PCOS Society criteria for the polycystic ovary syndrome: the complete task force report. Fertility and Sterility 91 456-488. (https://doi.org/10.1016/j. fertnstert.2008.06.035)

Balasch J, Fabregues F, Penarrubia J, Carmona F, Casamitjana R, Creus M, Manau D, Casals G \& Vanrell JA 2006 Pretreatment with transdermal testosterone may improve ovarian response to gonadotrophins in poor-responder IVF patients with normal basal concentrations of FSH. Human Reproduction 21 1884-1893. (https://doi.org/10.1093/humrep/ del052)

Banaszewska B, Wrotynska-Barczynska J, Spaczynski RZ, Pawelczyk L \& Duleba AJ 2016 Effects of resveratrol on polycystic ovary syndrome: a double-blind, randomized, placebo-controlled trial. Journal of Clinical Endocrinology and Metabolism 101 4322-4328. (https://doi. org/10.1210/jc.2016-1858)

Barad DH \& Gleicher N 2005 Increased oocyte production after treatment with dehydroepiandrosterone. Fertility and Sterility 84 756. (https:// doi.org/10.1016/j.fertnstert.2005.02.049)

Barad D \& Gleicher N 2006 Effect of dehydroepiandrosterone on oocyte and embryo yields, embryo grade and cell number in IVF. Human Reproduction 21 2845-2849. (https://doi.org/10.1093/humrep/del254)

Barad D, Brill H \& Gleicher N 2007 Update on the use of dehydroepiandrosterone supplementation among women with diminished ovarian function. Journal of Assisted Reproduction and Genetics 24 629-634. (https://doi.org/10.1007/s10815-007-9178-x)

Barbieri RL, Sluss PM, Powers RD, Mcshane PM, Vitonis A, Ginsburg E \& Cramer DC 2005 Association of body mass index, age, and cigarette smoking with serum testosterone levels in cycling women undergoing in vitro fertilization. Fertility and Sterility 83 302-308. (https://doi. org/10.1016/j.fertnstert.2004.07.956)

Barrenetxea G, Agirregoikoa JA, Jiménez MR, Lopez De Larruzea AL, Ganzabal T \& Carbonero K 2008 Ovarian response and pregnancy outcome in poor-responder women: a randomized controlled trial on the effect of luteinizing hormone supplementation on in vitro fertilization cycles. Fertility and Sterility 89 546-553. (https://doi. org/10.1016/j.fertnstert.2007.03.088)

Becerra-Fernandez A, Perez-Lopez G, Roman MM, Martin-Lazaro JF Lucio Perez MJ, Asenjo Araque N, Rodriguez-Molina JM, Berrocal Sertucha MC \& Aguilar Vilas MV 2014 Prevalence of hyperandrogenism and polycystic ovary syndrome in female to male transsexuals. Endocrinologia y Nutricion 61 351-358. (https://doi. org/10.1016/j.endonu.2014.01.010) https://joe.bioscientifica.com

https://doi.org/10.1530/JOE-19-0096
(C) 2019 Society for Endocrinology Published by Bioscientifica Ltd. Printed in Great Britain 
Benrick A, Chanclon B, Micallef P, Wu Y, Hadi L, Shelton JM, StenerVictorin E \& Wernstedt Asterholm I 2017 Adiponectin protects against development of metabolic disturbances in a PCOS mouse model. PNAS 114 E7187-E7196. (https://doi.org/10.1073/ pnas.1708854114)

Bercaire L, Nogueira SM, Lima PC, Alves VR, Donadio N, Dzik A \& Cavagna M 2018 ANDRO-IVF: a novel protocol for poor responders to IVF controlled ovarian stimulation. JBRA Assisted Reproduction 22 52-55. (https://doi.org/10.5935/1518-0557.20180011)

Berkkanoglu M, Isikoglu M, Aydin D \& Ozgur K 2007 Clinical effects of ovulation induction with recombinant follicle-stimulating hormone supplemented with recombinant luteinizing hormone or low-dose recombinant human chorionic gonadotropin in the midfollicular phase in microdose cycles in poor responders. Fertility and Sterility $\mathbf{8 8}$ 665-669. (https://doi.org/10.1016/j.fertnstert.2006.11.150)

Bertoldo MJ, Caldwell ASL, Riepsamen AH, Lin D, Gonzalez MB, Robker RL, Ledger WL, Gilchrist RB, Handelsman DJ \& Walters KA 2019 A hyperandrogenic environment causes intrinsic defects that are detrimental to follicular dynamics in a PCOS mouse model. Endocrinology 160 699-715. (https://doi.org/10.1210/en.2018-00966)

Bosdou JK, Venetis CA, Kolibianakis EM, Toulis KA, Goulis DG, Zepiridis L \& Tarlatzis BC 2012 The use of androgens or androgen-modulating agents in poor responders undergoing in vitro fertilization: a systematic review and meta-analysis. Human Reproduction Update $\mathbf{1 8}$ 127-145. (https://doi.org/10.1093/humupd/dmr051)

Bosdou JK, Venetis CA, Dafopoulos K, Zepiridis L, Chatzimeletiou K, Anifandis G, Mitsoli A, Makedos A, Messinis IE, Tarlatzis BC, et al. 2016 Transdermal testosterone pretreatment in poor responders undergoing ICSI: a randomized clinical trial. Human Reproduction $\mathbf{3 1}$ 977-985. (https://doi.org/10.1093/humrep/dew028)

Boyle JA \& Teede HJ 2016 PCOS: refining diagnostic features in PCOS to optimize health outcomes. Nature Reviews: Endocrinology 12 630-631. (https://doi.org/10.1038/nrendo.2016.157)

Bozdag G, Mumusoglu S, Zengin D, Karabulut E \& Yildiz BO 2016 The prevalence and phenotypic features of polycystic ovary syndrome: a systematic review and meta-analysis. Human Reproduction $\mathbf{3 1}$ 2841-2855. (https://doi.org/10.1093/humrep/dew218)

Brown RE, Wilkinson DA, Imran SA, Caraty A \& Wilkinson M 2012 Hypothalamic kiss1 mRNA and kisspeptin immunoreactivity are reduced in a rat model of polycystic ovary syndrome (PCOS). Brain Research 1467 1-9. (https://doi.org/10.1016/j.brainres.2012.05.049)

Burger HG 2002 Androgen production in women. Fertility and Sterility 77 (Supplement 4) S3-S5. (https://doi.org/10.1016/S00150282(02)02985-0)

Calaf J, López E, Millet A, Alcañiz J, Fortuny A, Vidal O, Callejo J, Escobar-Jiménez F, Torres E, Espinós JJ, et al. 2007 Long-term efficacy and tolerability of flutamide combined with oral contraception in moderate to severe hirsutism: a 12-month, double-blind, parallel clinical trial. Journal of Clinical Endocrinology and Metabolism 92 3446-3452. (https://doi.org/10.1210/jc.2006-2798)

Caldwell AS, Middleton LJ, Jimenez M, Desai R, Mcmahon AC, Allan CM Handelsman DJ \& Walters KA 2014 Characterization of reproductive, metabolic, and endocrine features of polycystic ovary syndrome in female hyperandrogenic mouse models. Endocrinology 155 3146-3159. (https://doi.org/10.1210/en.2014-1196)

Caldwell AS, Eid S, Kay CR, Jimenez M, Mcmahon AC, Desai R, Allan CM, Smith JT, Handelsman DJ \& Walters KA 2015 Haplosufficient genomic androgen receptor signaling is adequate to protect female mice from induction of polycystic ovary syndrome features by prenatal hyperandrogenization. Endocrinology 156 1441-1452. (https://doi. org/10.1210/en.2014-1887)

Caldwell ASL, Edwards MC, Desai R, Jimenez M, Gilchrist RB, Handelsman DJ \& Walters KA 2017 Neuroendocrine androgen action is a key extraovarian mediator in the development of polycystic ovary syndrome. PNAS 114 E3334-E3343. (https://doi.org/10.1073/ pnas.1616467114)
Cárdenas H \& Pope WF 1994 Administration of testosterone during the follicular phase increased the number of corpora lutea in gilts. Journal of Animal Science 72 2930-2935. (https://doi. org/10.2527/1994.72112930x)

Cardenas H, Herrick JR \& Pope WF 2002 Increased ovulation rate in gilts treated with dihydrotestosterone. Reproduction 123 527-533. (https:// doi.org/10.1530/rep.0.1230527)

Cardoso RC, Veiga-Lopez A, Moeller J, Beckett E, Pease A, Keller E, Madrigal V, Chazenbalk G, Dumesic D \& Padmanabhan V 2016 Developmental programming: impact of gestational steroid and metabolic milieus on adiposity and insulin sensitivity in prenatal testosterone-treated female sheep. Endocrinology 157 522-535. (https://doi.org/10.1210/en.2015-1565)

Casson PR, Lindsay MS, Pisarska MD, Carson SA \& Buster JE 2000 Dehydroepiandrosterone supplementation augments ovarian stimulation in poor responders: a case series. Human Reproduction $\mathbf{1 5}$ 2129-2132. (https://doi.org/10.1093/humrep/15.10.2129)

Cernea M, Padmanabhan V, Goodman RL, Coolen LM \& Lehman MN 2015 Prenatal testosterone treatment leads to changes in the morphology of KNDy neurons, their inputs, and projections to GnRH cells in female sheep. Endocrinology 156 3277-3291. (https://doi. org/10.1210/en.2014-1609)

Cheng XB, Jimenez M, Desai R, Middleton LJ, Joseph SR, Ning G, Allan CM, Smith JT, Handelsman DJ \& Walters KA 2013 Characterizing the neuroendocrine and ovarian defects of androgen receptor-knockout female mice. American Journal of Physiology: Endocrinology and Metabolism 305 E717-E726. (https://doi. org/10.1152/ajpendo.00263.2013)

Chern CU, Tsui KH, Vitale SG, Chen SN, Wang PH, Cianci A, Tsai HW, Wen ZH \& Lin LT 2018 Dehydroepiandrosterone (DHEA) supplementation improves in vitro fertilization outcomes of poor ovarian responders, especially in women with low serum concentration of DHEA-S: a retrospective cohort study. Reproductive Biology and Endocrinology 16 90. (https://doi.org/10.1186/s12958-0180409-z)

Conway G, Dewailly D, Diamanti-Kandarakis E, Escobar-Morreale HF, Franks S, Gambineri A, Kelestimur F, Macut D, Micic D, Pasquali R, et al. 2014 The polycystic ovary syndrome: a position statement from the European Society of Endocrinology. European Journal of Endocrinology 171 P1-29. (https://doi.org/10.1530/EJE-14-0253)

Couto Alves A, Valcarcel B, Mäkinen VP, Morin-Papunen L, Sebert S, Kangas AJ, Soininen P, Das S, De Iorio M, Coin L, et al. 2017 Metabolic profiling of polycystic ovary syndrome reveals interactions with abdominal obesity. International Journal of Obesity 41 1331-1340. (https://doi.org/10.1038/ijo.2017.126)

Daan NM, Jaspers L, Koster MP, Broekmans FJ, De Rijke YB, Franco OH, Laven JS, Kavousi M \& Fauser BC 2015 Androgen levels in women with various forms of ovarian dysfunction: associations with cardiometabolic features. Human Reproduction 30 2376-2386. (https:// doi.org/10.1093/humrep/dev195)

Daghestani MH 2018 Evaluation of biochemical, endocrine, and metabolic biomarkers for the early diagnosis of polycystic ovary syndrome among non-obese Saudi women. International Journal of Gynaecology and Obstetrics 142 162-169. (https://doi.org/10.1002/ ijgo.12527)

Davison SL \& Davis SR 2003 Androgens in women. Journal of Steroid Biochemistry and Molecular Biology 85 363-366. (https://doi. org/10.1016/S0960-0760(03)00204-8)

Davison SL, Bell R, Donath S, Montalto JG \& Davis SR 2005 Androgen levels in adult females: changes with age, menopause, and oophorectomy. Journal of Clinical Endocrinology and Metabolism 90 3847-3853. (https://doi.org/10.1210/jc.2005-0212)

De Leo V, Lanzetta D, D'Antona D, La Marca A \& Morgante G 1998 Hormonal effects of flutamide in young women with polycystic ovary syndrome. Journal of Clinical Endocrinology and Metabolism 83 99-102. (https://doi.org/10.1210/jcem.83.1.4500) 
De Roo C, Lierman S, Tilleman K, Peynshaert K, Braeckmans K, Caanen M, Lambalk CB, Weyers S, T'Sjoen G, Cornelissen R, et al. 2017 Ovarian tissue cryopreservation in female-to-male transgender people: insights into ovarian histology and physiology after prolonged androgen treatment. Reproductive Biomedicine Online 34 557-566. (https://doi.org/10.1016/j.rbmo.2017.03.008)

Diamanti-Kandarakis E, Mitrakou A, Raptis S, Tolis G \& Duleba AJ 1998 The effect of a pure antiandrogen receptor blocker, flutamide, on the lipid profile in the polycystic ovary syndrome. Journal of Clinical Endocrinology and Metabolism 83 2699-2705. (https://doi.org/10.1210/ jcem.83.8.5041)

Dickerson EH, Cho LW, Maguiness SD, Killick SL, Robinson J \& Atkin SL 2010 Insulin resistance and free androgen index correlate with the outcome of controlled ovarian hyperstimulation in non-PCOS women undergoing IVF. Human Reproduction 25 504-509. (https://doi. org/10.1093/humrep/dep393)

Diri H, Karaburgu S, Acmaz B, Unluhizarci K, Tanriverdi F, Karaca Z \& Kelestimur F 2016 Comparison of spironolactone and spironolactone plus metformin in the treatment of polycystic ovary syndrome. Gynecological Endocrinology 32 42-45. (https://doi.org/10.3109/09513 590.2015.1080679)

Doan HT, Quan LH \& Nguyen TT 2017 The effectiveness of transdermal testosterone gel 1\% (AndroGel) for poor responders undergoing in vitro fertilization. Gynecological Endocrinology 33 977-979. (https:// doi.org/10.1080/09513590.2017.1332586)

Dumesic DA, Oberfield SE, Stener-Victorin E, Marshall JC, Laven JS \& Legro RS 2015 Scientific statement on the diagnostic criteria, epidemiology, pathophysiology, and molecular genetics of polycystic ovary syndrome. Endocrine Reviews 36 487-525. (https://doi. org/10.1210/er.2015-1018)

Dumesic DA, Akopians AL, Madrigal VK, Ramirez E, Margolis DJ, Sarma MK, Thomas AM, Grogan TR, Haykal R, Schooler TA, et al. 2016 Hyperandrogenism accompanies increased intra-abdominal fat storage in normal weight polycystic ovary syndrome women. Journal of Clinical Endocrinology and Metabolism 101 4178-4188. (https://doi. org/10.1210/jc.2016-2586)

Eagleson CA, Gingrich MB, Pastor CL, Arora TK, Burt CM, Evans WS \& Marshall JC 2000 Polycystic ovarian syndrome: evidence that flutamide restores sensitivity of the gonadotropin-releasing hormone pulse generator to inhibition by estradiol and progesterone. Journal of Clinical Endocrinology and Metabolism 85 4047-4052. (https://doi. org/10.1210/jcem.85.11.6992)

Ebrahimi M, Akbari-Asbagh F \& Ghalandar-Attar M 2017 Letrozole+ GnRH antagonist stimulation protocol in poor ovarian responders undergoing intracytoplasmic sperm injection cycles: an RCT. International Journal of Reproductive BioMedicine 15 101-108. (https:// doi.org/10.29252/ijrm.15.2.101)

Ergenoglu M, Yildirim N, Yildirim AG, Yeniel O, Erbas O, Yavasoglu A, Taskiran D \& Karadadas N 2015 Effects of resveratrol on ovarian morphology, plasma anti-Mullerian hormone, IGF-1 levels, and oxidative stress parameters in a rat model of polycystic ovary syndrome. Reproductive Sciences 22 942-947. (https://doi. org/10.1177/1933719115570900)

Escobar-Morreale HF 2018 Polycystic ovary syndrome: definition, aetiology, diagnosis and treatment. Nature Reviews: Endocrinology 14 270-284. (https://doi.org/10.1038/nrendo.2018.24)

Fabregues F, Penarrubia J, Creus M, Manau D, Casals G, Carmona F \& Balasch J 2009 Transdermal testosterone may improve ovarian response to gonadotrophins in low-responder IVF patients: a randomized, clinical trial. Human Reproduction 24 349-359. (https:// doi.org/10.1093/humrep/den428)

Ferraretti AP, Gianaroli L, Magli MC, D’Angelo A, Farfalli V \& Montanaro N 2004 Exogenous luteinizing hormone in controlled ovarian hyperstimulation for assisted reproduction techniques. Fertility and Sterility 82 1521-1526. (https://doi.org/10.1016/j. fertnstert.2004.06.041)
Ferraretti AP, La Marca A, Fauser BC, Tarlatzis B, Nargund G, Gianaroli L \& ESHRE working group on Poor Ovarian Response Definition 2011 ESHRE consensus on the definition of 'poor response' to ovarian stimulation for in vitro fertilization: the Bologna criteria. Human Reproduction 26 1616-1624. (https://doi.org/10.1093/humrep/der092)

Ferraretti AP, Gianaroli L, Motrenko T, Feliciani E, Tabanelli C \& Magli MC 2014 LH pretreatment as a novel strategy for poor responders. BioMed Research International 2014 926172. (https://doi. org/10.1155/2014/926172)

Fraser GL, Ramael S, Hoveyda HR, Gheyle L \& Combalbert J 2016 The NK3 receptor antagonist ESN364 suppresses sex hormones in men and women. Journal of Clinical Endocrinology and Metabolism 101 417-426. (https://doi.org/10.1210/jc.2015-3621)

Frattarelli JL \& Peterson EH 2004 Effect of androgen levels on in vitro fertilization cycles. Fertility and Sterility 81 1713-1714. (https://doi. org/10.1016/j.fertnstert.2003.11.032)

Futterweit W \& Deligdisch L 1986 Histopathological effects of exogenously administered testosterone in 19 female to male transsexuals. Journal of Clinical Endocrinology and Metabolism 62 16-21. (https://doi.org/10.1210/jcem-62-1-16)

Gambineri A, Patton L, Vaccina A, Cacciari M, Morselli-Labate AM, Cavazza C, Pagotto U \& Pasquali R 2006. Treatment with flutamide, metformin, and their combination added to a hypocaloric diet in overweight-obese women with polycystic ovary syndrome: a randomized, 12-month, placebo-controlled study. Journal of Clinical Endocrinology and Metabolism 91 3970-3980. (https://doi.org/10.1210/ jc. 2005-2250)

Garcia-Velasco JA, Moreno L, Pacheco A, Guillen A, Duque L, Requena A \& Pellicer A 2005 The aromatase inhibitor letrozole increases the concentration of intraovarian androgens and improves in vitro fertilization outcome in low responder patients: a pilot study. Fertility and Sterility 84 82-87. (https://doi.org/10.1016/j. fertnstert.2005.01.117)

George JT, Kakkar R, Marshall J, Scott ML, Finkelman RD, Ho TW, Veldhuis J, Skorupskaite K, Anderson RA, Mcintosh S, et al. 2016 Neurokinin B receptor antagonism in women with polycystic ovary syndrome: a randomized, placebo-controlled trial. Journal of Clinical Endocrinology and Metabolism 101 4313-4321. (https://doi. org/10.1210/jc.2016-1202)

Gill A, Jamnongjit M \& Hammes SR 2004 Androgens promote maturation and signaling in mouse oocytes independent of transcription: a release of inhibition model for mammalian oocyte meiosis. Molecular Endocrinology 18 97-104. (https://doi.org/10.1210/me.2003-0326)

Gleicher N \& Barad DH 2011 Dehydroepiandrosterone (DHEA) supplementation in diminished ovarian reserve (DOR). Reproductive Biology and Endocrinology 9 67. (https://doi.org/10.1186/1477-78279-67)

Gonzalez-Comadran M, Duran M, Sola I, Fabregues F, Carreras R \& Checa MA 2012 Effects of transdermal testosterone in poor responders undergoing IVF: systematic review and meta-analysis. Reproductive Biomedicine Online 25 450-459. (https://doi.org/10.1016/j. rbmo.2012.07.011)

Goswami SK, Das T, Chattopadhyay R, Sawhney V, Kumar J, Chaudhury K, Chakravarty BN \& Kabir SN 2004 A randomized singleblind controlled trial of letrozole as a low-cost IVF protocol in women with poor ovarian response: a preliminary report. Human Reproduction 19 2031-2035. (https://doi.org/10.1093/humrep/deh359)

Gougeon A 1996 Regulation of ovarian follicular development in primates: facts and hypotheses. Endocrine Reviews 17 121-155. (https://doi.org/10.1210/edrv-17-2-121)

Goverde AJ, Mcdonnell J, Schats R, Vermeiden JP, Homburg R \& Lambalk CB 2005 Ovarian response to standard gonadotrophin stimulation for IVF is decreased not only in older but also in younger women in couples with idiopathic and male subfertility. Human Reproduction 20 1573-1577. (https://doi.org/10.1093/humrep/ deh827) https://joe.bioscientifica.com https://doi.org/10.1530/JOE-19-0096 (c) 2019 Society for Endocrinology Published by Bioscientifica Ltd. Printed in Great Britain 
Hague WM, Adams J, Rodda C, Brook CGD, De Bruyn R, Grant DB \& Jacobs HS 1990 The prevalence of polycystic ovaries in patients WITH congenital adrenal hyperplasia and their close relatives. Clinical Endocrinology 33 501-510. (https://doi.org/10.1111/j.1365-2265.1990. tb03887.x)

Hampton JH, Manikkam M, Lubahn DB, Smith MF \& Garverick HA 2004 Androgen receptor mRNA expression in the bovine ovary. Domestic Animal Endocrinology 27 81-88. (https://doi.org/10.1016/j. domaniend.2004.01.005)

Harlow CR, Hillier SG \& Hodges JK 1986 Androgen modulation of follicle-stimulating hormone-induced granulosa cell steroidogenesis in the primate ovary. Endocrinology 119 1403-1405. (https://doi. org/10.1210/endo-119-3-1403)

Haydardedeoglu B, Isik AZ \& Bulgan Kilicdag E 2015 The combination of dehydroepiandrosterone, transdermal testosterone, and growth hormone as an adjuvant therapy in assisted reproductive technology cycles in patients aged below 40 years with diminished ovarian reserve. Turkish Journal of Obstetrics and Gynecology 12 60-65. (https:// doi.org/10.4274/tjod.32656)

Hild-Petito S, West NB, Brenner RM \& Stouffer RL 1991 Localization of androgen receptor in the follicle and corpus luteum of the primate ovary during the menstrual cycle. Biology of Reproduction 44 561-568. (https://doi.org/10.1095/biolreprod44.3.561)

Hillier SG \& De Zwart FA 1981 Evidence that granulosa cell aromatase induction/activation by follicle-stimulating hormone is an androgen receptor-regulated process in-vitro. Endocrinology 109 1303-1305. (https://doi.org/10.1210/endo-109-4-1303)

Hillier SG, Whitelaw PF \& Smyth CD 1994 Follicular oestrogen synthesis: the 'two-cell, two-gonadotrophin' model revisited. Molecular and Cellular Endocrinology 100 51-54. (https://doi.org/10.1016/03037207(94)90278-X)

Homan GF, Davies M \& Norman R 2007 The impact of lifestyle factors on reproductive performance in the general population and those undergoing infertility treatment: a review. Human Reproduction Update 13 209-223. (https://doi.org/10.1093/humupd/dml056)

Horie K, Takakura K, Fujiwara H, Suginami H, Liao S \& Mori T 1992 Immunohistochemical localization of androgen receptor in the human ovary throughout the menstrual cycle in relation to oestrogen and progesterone receptor expression. Human Reproduction 7 184-190. (https://doi.org/10.1093/oxfordjournals.humrep.a137614)

Hu YC, Wang PH, Yeh S, Wang RS, Xie C, Xu Q, Zhou X, Chao HT, Tsai MY \& Chang C 2004 Subfertility and defective folliculogenesis in female mice lacking androgen receptor. PNAS 101 11209-11214. (https://doi.org/10.1073/pnas.0404372101)

Hu Q, Hong L, Nie M, Wang Q, Fang Y, Dai Y, Zhai Y, Wang S, Yin C \& Yang X 2017 The effect of dehydroepiandrosterone supplementation on ovarian response is associated with androgen receptor in diminished ovarian reserve women. Journal of Ovarian Research 10 32-32. (https://doi.org/10.1186/s13048-017-0326-3)

Huang X \& Harlan RE 1993 Absence of androgen receptors in LHRH immunoreactive neurons. Brain Research 624 309-311. (https://doi. org/10.1016/0006-8993(93)90094-4)

Humaidan P, Bungum L, Bungum M \& Andersen CY 2002 Ovarian response and pregnancy outcome related to mid-follicular $\mathrm{LH}$ levels in women undergoing assisted reproduction with GnRH agonist down-regulation and recombinant FSH stimulation. Human Reproduction 17 2016-2021. (https://doi.org/10.1093/ humrep/17.8.2016)

Jeve YB \& Bhandari HM 2016 Effective treatment protocol for poor ovarian response: a systematic review and meta-analysis. Journal of Human Reproductive Sciences 9 70-81. (https://doi.org/10.4103/09741208.183515)

Ji J, Ju X, Wang J, Wu H \& Fan H 2016 Effectiveness of dehydroepiandrosterone in poor ovarian responders undergoing in vitro fertilization: a meta-analysis of randomized controlled trials.
International Journal of Clinical and Experimental Medicine 9 20835-20845.

Jirge PR, Chougule SM, Gavali VG \& Bhomkar DA 2014 Impact of dehydroepiandrosterone on clinical outcome in poor responders: a pilot study in women undergoing in vitro fertilization, using bologna criteria. Journal of Human Reproductive Sciences 7 175-180. (https://doi. org/10.4103/0974-1208.142477)

Jovanovic VP, Kort DH, Guarnaccia MM, Sauer MV \& Lobo RA 2011 Does the addition of clomiphene citrate or letrazole to gonadotropin treatment enhance the oocyte yield in poor responders undergoing IVF? Journal of Assisted Reproduction and Genetics 28 1067-1072. (https://doi.org/10.1007/s10815-011-9643-4)

Juengel JL, Heath DA, Quirke LD \& McNatty KP 2006 Oestrogen receptor alpha and beta, androgen receptor and progesterone receptor mRNA and protein localisation within the developing ovary and in small growing follicles of sheep. Reproduction 131 81-92. (https://doi. org/10.1530/rep.1.00704)

Kamath MS, Maheshwari A, Bhattacharya S, Lor KY \& Gibreel A 2017 Oral medications including clomiphene citrate or aromatase inhibitors with gonadotropins for controlled ovarian stimulation in women undergoing in vitro fertilisation. Cochrane Database of Systematic Reviews 11 CD008528. (https://doi.org/10.1002/14651858. CD008528.pub3)

Kara M, Aydin T, Aran T, Turktekin N \& Ozdemir B 2014 Does dehydroepiandrosterone supplementation really affect IVF-ICSI outcome in women with poor ovarian reserve? European Journal of Obstetrics, Gynecology, and Reproductive Biology 173 63-65. (https://doi. org/10.1016/j.ejogrb.2013.11.008)

Katulski K, Podfigurna A, Czyzyk A, Meczekalski B \& Genazzani AD 2018 Kisspeptin and LH pulsatile temporal coupling in PCOS patients. Endocrine 61 149-157. (https://doi.org/10.1007/s12020-018-1609-1)

Kauffman AS, Thackray VG, Ryan GE, Tolson KP, Glidewell-Kenney CA, Semaan SJ, Poling MC, Iwata N, Breen KM, Duleba AJ, et al. 2015 A novel letrozole model recapitulates both the reproductive and metabolic phenotypes of polycystic ovary syndrome in female mice. Biology of Reproduction 93 69. (https://doi.org/10.1095/ biolreprod.115.131631)

Keefe CC, Goldman MM, Zhang K, Clarke N, Reitz RE \& Welt CK 2014 Simultaneous measurement of thirteen steroid hormones in women with polycystic ovary syndrome and control women using liquid chromatography-tandem mass spectrometry. PLOS ONE 9 e93805. (https://doi.org/10.1371/journal.pone.0093805)

Keller E, Chazenbalk GD, Aguilera P, Madrigal V, Grogan T, Elashoff D, Dumesic DA \& Abbott DH 2014 Impaired preadipocyte differentiation into adipocytes in subcutaneous abdominal adipose of PCOS-like female rhesus monkeys. Endocrinology 155 2696-2703. (https://doi. org/10.1210/en.2014-1050)

Kim CH, Howles CM \& Lee HA 2011 The effect of transdermal testosterone gel pretreatment on controlled ovarian stimulation and IVF outcome in low responders. Fertility and Sterility 95 679-683. (https://doi.org/10.1016/j.fertnstert.2010.07.1077)

Kim CH, Ahn JW, Moon JW, Kim SH, Chae HD \& Kang BM 2014 Ovarian features after 2 weeks, 3 weeks and 4 weeks transdermal testosterone gel treatment and their associated effect on IVF outcomes in poor responders. Development and Reproduction 18 145-152. (https://doi. org/10.12717/DR.2014.18.3.145)

Kotb MM, Hassan AM \& Awadallah AM 2016 Does dehydroepiandrosterone improve pregnancy rate in women undergoing IVF/ICSI with expected poor ovarian response according to the Bologna criteria? A randomized controlled trial. European Journal of Obstetrics, Gynecology, and Reproductive Biology 200 11-15. (https://doi.org/10.1016/j.ejogrb.2016.02.009)

Kuhn R \& Torres RM 2002 Cre/loxP recombination system and gene targeting. Methods in Molecular Biology 180 175-204. (https://doi. org/10.1385/1-59259-178-7:175) https://joe.bioscientifica.com https://doi.org/10.1530/JOE-19-0096
(C) 2019 Society for Endocrinology Published by Bioscientifica Ltd. Printed in Great Britain 
Kumari GL, Datta JK \& Roy S 1978 Evidence for a role of androgens in the growth and maturation of ovarian follicles in rats. Hormone Research 9 112-120. (https://doi.org/10.1159/000178903)

Laird M, Thomson K, Fenwick M, Mora J, Franks S \& Hardy K 2017 Androgen stimulates growth of mouse preantral follicles in vitro: interaction with follicle-stimulating hormone and with growth factors of the TGFbeta superfamily. Endocrinology 158 920-935. (https://doi.org/10.1210/en.2016-1538)

Lakryc EM, Motta EL, Soares JM, Haidar MA, de Lima GR \& Baracat EC 2003 The benefits of finasteride for hirsute women with polycystic ovary syndrome or idiopathic hirsutism. Gynecological Endocrinology 17 57-63. (https://doi.org/10.1080/713603187)

Lebbe M, Taylor AE, Visser JA, Kirkman-Brown JC, Woodruff TK \& Arlt W 2017 The steroid metabolome in the isolated ovarian follicle and its response to androgen exposure and antagonism. Endocrinology 158 1474-1485. (https://doi.org/10.1210/en.2016-1851)

Lee KH, Kim CH, Suk HJ, Lee YJ, Kwon SK, Kim SH, Chae HD \& Kang BM 2014 The effect of aromatase inhibitor letrozole incorporated in gonadotrophin-releasing hormone antagonist multiple dose protocol in poor responders undergoing in vitro fertilization. Obstetrics and Gynecology Science 57 216-222. (https://doi.org/10.5468/ ogs.2014.57.3.216)

Lee BH, Indran IR, Tan HM, Li Y, Zhang Z, Li J \& Yong EL 2016 A dietary medium-chain fatty acid, decanoic acid, inhibits recruitment of Nur77 to the HSD3B2 promoter in vitro and reverses endocrine and metabolic abnormalities in a rat model of polycystic ovary syndrome. Endocrinology 157 382-394. (https://doi.org/10.1210/ en.2015-1733)

Legro RS, Arslanian SA, Ehrmann DA, Hoeger KM, Murad MH, Pasquali R, Welt CK \& Endocrine Society 2013 Diagnosis and treatment of polycystic ovary syndrome: an Endocrine Society clinical practice guideline. Journal of Clinical Endocrinology and Metabolism 98 4565-4592. (https://doi.org/10.1210/jc.2013-2350)

Lenie S \& Smitz J 2009 Functional AR signaling is evident in an in vitro mouse follicle culture bioassay that encompasses most stages of folliculogenesis. Biology of Reproduction 80 685-695. (https://doi. org/10.1095/biolreprod.107.067280)

Li M, Ai JS, Xu BZ, Xiong B, Yin S, Lin SL, Hou Y, Chen DY, Schatten H \& Sun QY 2008 Testosterone potentially triggers meiotic resumption by activation of intra-oocyte SRC and MAPK in porcine oocytes. Biology of Reproduction 79 897-905. (https://doi.org/10.1095/ biolreprod.108.069245)

Li H, Xu X, Wang X, Liao X, Li L, Yang G \& Gao L 2016 Free androgen index and Irisin in polycystic ovary syndrome. Journal of Endocrinological Investigation 39 549-556. (https://doi.org/10.1007/ s40618-015-0403-7)

Li CJ, Chen SN, Lin LT, Chern CU, Wang PH, Wen ZH \& Tsui KH 2018 Dehydroepiandrosterone ameliorates abnormal mitochondrial dynamics and mitophagy of cumulus cells in poor ovarian responders. Journal of Clinical Medicine 7 E293. (https://doi. org/10.3390/jcm7100293)

Lin LT, Wang PH, Wen ZH, Li CJ, Chen SN, Tsai EM, Cheng JT \& Tsui KH 2017 The application of dehydroepiandrosterone on improving mitochondrial function and reducing apoptosis of cumulus cells in poor ovarian responders. International Journal of Medical Sciences $\mathbf{1 4}$ 585-594. (https://doi.org/10.7150/ijms.18706)

Liu D, Iruthayanathan M, Homan LL, Wang Y, Yang L, Wang Y \& Dillon JS 2008 Dehydroepiandrosterone stimulates endothelial proliferation and angiogenesis through extracellular signal-regulated kinase 1/2-mediated mechanisms. Endocrinology 149 889-898. (https://doi.org/10.1210/en.2007-1125)

Liu Y, Hu L, Fan L \& Wang F 2018 Efficacy of dehydroepiandrosterone (DHEA) supplementation for in vitro fertilization and embryo transfer cycles: a systematic review and meta-analysis. Gynecological Endocrinology 34 178-183. (https://doi.org/10.1080/09513590.2017.1 391202)
Livadas S, Pappas C, Karachalios A, Marinakis E, Tolia N, Drakou M, Kaldrymides P, Panidis D \& Diamanti-Kandarakis E 2014 Prevalence and impact of hyperandrogenemia in 1,218 women with polycystic ovary syndrome. Endocrine 47 631-638. (https://doi.org/10.1007/ s12020-014-0200-7)

Lu Q, Shen H, Li Y, Zhang C, Wang C, Chen X, Liang R \& Wei L 2014 Low testosterone levels in women with diminished ovarian reserve impair embryo implantation rate: a retrospective case-control study. Journal of Assisted Reproduction and Genetics 31 485-491. (https://doi. org/10.1007/s10815-014-0186-3)

Lucis OJ, Hobkirk R, Hollenberg CH, Macdonald SA \& Blahey P 1966 Polycystic ovaries associated with congenital adrenal hyperplasia. Canadian Medical Association Journal 94 1-7.

Luo S, Li S, Li X, Qin L \& Jin S 2014 Effect of pretreatment with transdermal testosterone on poor ovarian responders undergoing IVF/ICSI: a meta-analysis. Experimental and Therapeutic Medicine $\mathbf{8}$ 187-194. (https://doi.org/10.3892/etm.2014.1683)

Ma Y, Andrisse S, Chen Y, Childress S, Xue P, Wang Z, Jones D, Ko C, Divall S \& Wu S 2017 Androgen receptor in the ovary theca cells plays a critical role in androgen-induced reproductive dysfunction. Endocrinology 158 98-108. (https://doi.org/10.1210/en.2016-1608)

Manneras-Holm L, Leonhardt H, Kullberg J, Jennische E, Oden A, Holm G, Hellstrom M, Lonn L, Olivecrona G, Stener-Victorin E, et al. 2011 Adipose tissue has aberrant morphology and function in PCOS enlarged adipocytes and low serum adiponectin, but not circulating sex steroids, are strongly associated with insulin resistance. Journal of Clinical Endocrinology and Metabolism 96 E304-E311. (https://doi. org/10.1210/jc.2010-1290)

March WA, Moore VM, Willson KJ, Phillips DI, Norman RJ \& Davies MJ 2010 The prevalence of polycystic ovary syndrome in a community sample assessed under contrasting diagnostic criteria. Human Reproduction 25 544-551. (https://doi.org/10.1093/humrep/dep399)

Marti N, Bouchoucha N, Sauter KS \& Fluck CE 2017 Resveratrol inhibits androgen production of human adrenocortical H295R cells by lowering CYP17 and CYP21 expression and activities. PLOS ONE 12 e0174224. (https://doi.org/10.1371/journal.pone.0174224)

Massin N, Cedrin-Durnerin I, Coussieu C, Galey-Fontaine J, Wolf JP \& Hugues JN 2006 Effects of transdermal testosterone application on the ovarian response to FSH in poor responders undergoing assisted reproduction technique - a prospective, randomized, double-blind study. Human Reproduction 21 1204-1211. (https://doi.org/10.1093/ humrep/dei481)

McEwan IJ, Mcguinness D, Hay CW, Millar RP, Saunders PT \& Fraser HM 2010 Identification of androgen receptor phosphorylation in the primate ovary in vivo. Reproduction 140 93-104. (https://doi. org/10.1530/REP-10-0140)

Mendoza N, Simoncini T \& Genazzani AD 2014 Hormonal contraceptive choice for women with PCOS: a systematic review of randomized trials and observational studies. Gynecological Endocrinology 30 850-860. (https://doi.org/10.3109/09513590.2014.943725)

Mitri F, Behan LA, Murphy CA, Hershko-Klement A, Casper RF \& Bentov Y 2016 Microdose flare protocol with interrupted follicle stimulating hormone and added androgen for poor responders - an observational pilot study. Fertility and Sterility 105 100.e1-105.e1. (https://doi.org/10.1016/j.fertnstert.2015.09.038)

Mitwally MF \& Casper RF 2002 Aromatase inhibition improves ovarian response to follicle-stimulating hormone in poor responders. Fertility and Sterility 77 776-780. (https://doi.org/10.1016/S00150282(01)03280-0)

Moawad A \& Shaeer M 2012 Long-term androgen priming by use of dehydroepiandrosterone (DHEA) improves IVF outcome in poorresponder patients. A randomized controlled study. Middle East Fertility Society Journal 17 268-274. (https://doi.org/10.1016/j. mefs.2012.11.002)

Moghetti P, Tosi F, Tosti A, Negri C, Misciali C, Perrone F, Caputo M, Muggeo M \& Castello R 2000 Comparison of spironolactone, 
flutamide, and finasteride efficacy in the treatment of hirsutism: a randomized, double blind, placebo-controlled trial. Journal of Clinical Endocrinology and Metabolism 85 89-94. (https://doi.org/10.1210/ jcem.85.1.6245)

Mohsen IA \& El Din RE 2013 Minimal stimulation protocol using letrozole versus microdose flare up GnRH agonist protocol in women with poor ovarian response undergoing ICSI. Gynecological Endocrinology 29 105-108. (https://doi.org/10.3109/09513590.2012. 730569)

Moore AM, Prescott M \& Campbell RE 2013 Estradiol negative and positive feedback in a prenatal androgen-induced mouse model of polycystic ovarian syndrome. Endocrinology 154 796-806. (https://doi. org/10.1210/en.2012-1954)

Moore AM, Prescott M, Marshall CJ, Yip SH \& Campbell RE 2015 Enhancement of a robust arcuate GABAergic input to gonadotropinreleasing hormone neurons in a model of polycystic ovarian syndrome. PNAS 112 596-601. (https://doi.org/10.1073/ pnas.1415038112)

Moran LJ, Norman RJ \& Teede HJ 2015 Metabolic risk in PCOS: phenotype and adiposity impact. Trends in Endocrinology and Metabolism 26 136-143. (https://doi.org/10.1016/j.tem.2014.12.003)

Mumme K \& Stonehouse W 2015 Effects of medium-chain triglycerides on weight loss and body composition: a meta-analysis of randomized controlled trials. Journal of the Academy of Nutrition and Dietetics 115 249-263. (https://doi.org/10.1016/j.jand.2014.10.022)

Murray AA, Gosden RG, Allison V \& Spears N 1998 Effect of androgens on the development of mouse follicles growing in vitro. Journal of Reproduction and Fertility 113 27-33. (https://doi.org/10.1530/ jrf.0.1130027)

Nagels HE, Rishworth JR, Siristatidis CS \& Kroon B 2015 Androgens (dehydroepiandrosterone or testosterone) for women undergoing assisted reproduction. Cochrane Database of Systematic Reviews CD009749. (https://doi.org/10.1002/14651858.CD009749.pub2)

Nakhjavani M, Hamidi S, Esteghamati A, Abbasi M, Nosratian-Jahromi S \& Pasalar P 2009 Short term effects of spironolactone on blood lipid profile: a 3-month study on a cohort of young women with hirsutism. British Journal of Clinical Pharmacology 68 634-637. (https://doi. org/10.1111/j.1365-2125.2009.03483.x)

Narkwichean A, Jayaprakasan K, Maalouf WE, HernandezMedrano JH, Pincott-Allen C \& Campbell BK 2014 Effects of dehydroepiandrosterone on in vivo ovine follicular development. Human Reproduction 29 146-154. (https://doi.org/10.1093/humrep/ $\operatorname{det} 408)$

Narkwichean A, Maalouf W, Baumgarten M, Polanski L, RaineFenning N, Campbell B \& Jayaprakasan K 2017 Efficacy of dehydroepiandrosterone (DHEA) to overcome the effect of ovarian ageing (DITTO): a proof of principle double blinded randomized placebo controlled trial. European Journal of Obstetrics, Gynecology, and Reproductive Biology 218 39-48. (https://doi.org/10.1016/j. ejogrb.2017.09.006)

Navarro VM, Gottsch ML, Chavkin C, Okamura H, Clifton DK \& Steiner RA 2009 Regulation of gonadotropin-releasing hormone secretion by kisspeptin/dynorphin/neurokinin B neurons in the arcuate nucleus of the mouse. Journal of Neuroscience 29 11859-11866. (https://doi.org/10.1523/JNEUROSCI.1569-09.2009)

Nelson VL, Legro RS, Strauss JF III \& Mcallister JM 1999 Augmented androgen production is a stable steroidogenic phenotype of propagated theca cells from polycystic ovaries. Molecular Endocrinology 13 946-957. (https://doi.org/10.1210/mend.13.6.0311)

Nielsen ME, Rasmussen IA, Kristensen SG, Christensen ST, Mollgard K, Wreford Andersen E, Byskov AG \& Yding Andersen C 2011 In human granulosa cells from small antral follicles, androgen receptor mRNA and androgen levels in follicular fluid correlate with FSH receptor mRNA. Molecular Human Reproduction 17 63-70. (https://doi. org/10.1093/molehr/gaq073)
Nohara K, Laque A, Allard C, Munzberg H \& Mauvais-Jarvis F 2014 Central mechanisms of adiposity in adult female mice with androgen excess. Obesity 22 1477-1484. (https://doi.org/10.1002/oby.20719)

Noventa M, Vitagliano A, Andrisani A, Blaganje M, Vigano P, Papaelo E, Scioscia M, Cavallin F, Ambrosini G \& Cozzolino M 2019 Testosterone therapy for women with poor ovarian response undergoing IVF: a meta-analysis of randomized controlled trials. Journal of Assisted Reproduction and Genetics 36 673-683. (https://doi.org/10.1007/ s10815-018-1383-2)

O'Reilly MW, Kempegowda P, Jenkinson C, Taylor AE, Quanson JL, Storbeck KH \& Arlt W 2017 11-Oxygenated C19 steroids are the predominant androgens in polycystic ovary syndrome. Journal of Clinical Endocrinology and Metabolism 102 840-848. (https://doi. org/10.1210/jc.2016-3285)

Osuka S, Iwase A, Nakahara T, Kondo M, Saito A, Bayasula, Nakamura T, Takikawa S, Goto M, Kotani T \& Kikkawa F 2017 Kisspeptin in the hypothalamus of 2 rat models of polycystic ovary syndrome. Endocrinology 158 367-377. (https://doi.org/10.1210/en.2016-1333)

Ozmen B, Sonmezer M, Atabekoglu CS \& Olmus H 2009 Use of aromatase inhibitors in poor-responder patients receiving GnRH antagonist protocols. Reproductive Biomedicine Online 19 478-485. (https://doi. org/10.1016/j.rbmo.2009.05.007)

Padmanabhan V \& Veiga-Lopez A 2013 Sheep models of polycystic ovary syndrome phenotype. Molecular and Cellular Endocrinology 373 8-20. (https://doi.org/10.1016/j.mce.2012.10.005)

Padmanabhan V, Veiga-Lopez A, Herkimer C, Abi Salloum B, Moeller J, Beckett E \& Sreedharan R 2015 Developmental programming: prenatal and postnatal androgen antagonist and insulin sensitizer interventions prevent advancement of puberty and improve LH surge dynamics in prenatal testosterone-treated sheep. Endocrinology 156 2678-2692. (https://doi.org/10.1210/en.2015-1235)

Palomba S, Falbo A, Chiossi G, Muscogiuri G, Fornaciari E, Orio F, Tolino A, Colao A, La Sala GB \& Zullo F 2014 Lipid profile in nonobese pregnant women with polycystic ovary syndrome: a prospective controlled clinical study. Steroids 88 36-43. (https://doi. org/10.1016/j.steroids.2014.06.005)

Paradisi R, Fabbri R, Battaglia C \& Venturoli S 2013 Ovulatory effects of flutamide in the polycystic ovary syndrome. Gynecological Endocrinology 29 391-395. (https://doi.org/10.3109/09513590.2012. 754876)

Polyzos NP \& Devroey P 2011 A systematic review of randomized trials for the treatment of poor ovarian responders: is there any light at the end of the tunnel? Fertility and Sterility 96 1058-61.e7. (https://doi. org/10.1016/j.fertnstert.2011.09.048)

Polyzos NP, Davis SR, Drakopoulos P, Humaidan P, De Geyter C, Vega AG, Martinez F, Evangelou E, Van De Vijver A, Smitz J, et al. 2018 Testosterone for poor ovarian responders: lessons from ovarian physiology. Reproductive Sciences 25 980-982. (https://doi. org/10.1177/1933719116660849)

Quigley CA, De Bellis A, Marschke KB, El-Awady MK, Wilson EM \& French FS 1995 Androgen receptor defects: historical, clinical, and molecular perspectives. Endocrine Reviews 16 271-321. (https://doi. org/10.1210/edrv-16-3-271)

Roland AV, Nunemaker CS, Keller SR \& Moenter SM 2010 Prenatal androgen exposure programs metabolic dysfunction in female mice. Journal of Endocrinology 207 213-223. (https://doi.org/10.1677/JOE10-0217)

Romero S \& Smitz J 2010 Exposing cultured mouse ovarian follicles under increased gonadotropin tonus to aromatizable androgens influences the steroid balance and reduces oocyte meiotic capacity. Endocrine $\mathbf{3 8}$ 243-253. (https://doi.org/10.1007/s12020-010-9380-y)

Rotterdam ESHRE/ASRM-Sponsored PCOS Consensus Workshop Group 2004 Revised 2003 consensus on diagnostic criteria and long-term health risks related to polycystic ovary syndrome (PCOS). Human Reproduction 19 41-47. (https://doi.org/10.1093/humrep/deh098) https://joe.bioscientifica.com

https://doi.org/10.1530/JOE-19-0096
(C) 2019 Society for Endocrinology Published by Bioscientifica Ltd. Printed in Great Britain 
Ruvolo G, Bosco L, Pane A, Morici G, Cittadini E \& Roccheri MC 2007 Lower apoptosis rate in human cumulus cells after administration of recombinant luteinizing hormone to women undergoing ovarian stimulation for in vitro fertilization procedures. Fertility and Sterility 87 542-546. (https://doi.org/10.1016/j.fertnstert.2006.06.059)

Saharkhiz N, Zademodares S, Salehpour S, Hosseini S, Nazari L \& Tehrani HG 2018 The effect of testosterone gel on fertility outcomes in women with a poor response in in vitro fertilization cycles: a pilot randomized clinical trial. Journal of Research in Medical Sciences 23 3-3. (https://doi.org/10.4103/jrms.JRMS_864_17)

Sarma HN, Manikkam M, Herkimer C, Dell'Orco J, Welch KB, Foster DL \& Padmanabhan V 2005 Fetal programming: excess prenatal testosterone reduces postnatal luteinizing hormone, but not folliclestimulating hormone responsiveness, to estradiol negative feedback in the female. Endocrinology 146 4281-4291. (https://doi.org/10.1210/ en.2005-0322)

Schoolcraft WB, Surrey ES, Minjarez DA, Stevens JM \& Gardner DK 2008 Management of poor responders: can outcomes be improved with a novel gonadotropin-releasing hormone antagonist/letrozole protocol? Fertility and Sterility 89 151-156. (https://doi.org/10.1016/j. fertnstert.2007.02.013)

Schwarze JE, Canales J, Crosby J, Ortega-Hrepich C, Villa S \& Pommer R 2018 DHEA use to improve likelihood of IVF/ICSI success in patients with diminished ovarian reserve: a systematic review and meta-analysis. JBRA Assisted Reproduction 22 369-374. (https://doi. org/10.5935/1518-0557.20180046)

Sen A \& Hammes SR 2010 Granulosa cell-specific androgen receptors are critical regulators of ovarian development and function. Molecular Endocrinology 24 1393-1403. (https://doi.org/10.1210/me.2010-0006)

Sen A, Prizant H, Light A, Biswas A, Hayes E, Lee HJ, Barad D, Gleicher N \& Hammes SR 2014 Androgens regulate ovarian follicular development by increasing follicle stimulating hormone receptor and microRNA-125b expression. PNAS 111 3008-3013. (https://doi. org/10.1073/pnas.1318978111)

Sheppard KM, Padmanabhan V, Coolen LM \& Lehman MN 2011 Prenatal programming by testosterone of hypothalamic metabolic control neurones in the ewe. Journal of Neuroendocrinology 23 401-411. (https://doi.org/10.1111/j.1365-2826.2011.02126.x)

Shiina H, Matsumoto T, Sato T, Igarashi K, Miyamoto J, Takemasa S, Sakari M, Takada I, Nakamura T, Metzger D, et al. 2006 Premature ovarian failure in androgen receptor-deficient mice. PNAS 103 224-229. (https://doi.org/10.1073/pnas.0506736102)

Shorakae S, Boyle J \& Teede H 2014 Polycystic ovary syndrome: a common hormonal condition with major metabolic sequelae that physicians should know about. Internal Medicine Journal 44 720-726. (https://doi.org/10.1111/imj.12495)

Simpson ER, Clyne C, Rubin G, Boon WC, Robertson K, Britt K, Speed C \& Jones M 2002 Aromatase - a brief overview. Annual Review of Physiology 64 93-127. (https://doi.org/10.1146/annurev. physiol.64.081601.142703)

Singh A, Bora P \& Krishna A 2017 Systemic adiponectin treatment reverses polycystic ovary syndrome-like features in an animal model. Reproduction, Fertility, and Development 30 571-584. (https://doi. org/10.1071/RD17255)

Sipe CS, Thomas MR, Stegmann BJ \& Van Voorhis BJ 2010 Effects of exogenous testosterone supplementation in gonadotrophin stimulated cycles. Human Reproduction 25 690-696. (https://doi. org/10.1093/humrep/dep442)

Skiba MA, Islam RM, Bell RJ \& Davis SR 2018 Understanding variation in prevalence estimates of polycystic ovary syndrome: a systematic review and meta-analysis. Human Reproduction Update 24 694-709. (https://doi.org/10.1093/humupd/dmy022)

Skorupskaite K, George JT \& Anderson RA 2014 The kisspeptin-GnRH pathway in human reproductive health and disease. Human Reproduction Update 20 485-500. (https://doi.org/10.1093/humupd/ dmu009)
Slomczynska M \& Tabarowski Z 2001 Localization of androgen receptor and cytochrome P450 aromatase in the follicle and corpus luteum of the porcine ovary. Animal Reproduction Science 65 127-134. (https:// doi.org/10.1016/S0378-4320(00)00225-6)

Smith JT 2013 Sex steroid regulation of kisspeptin circuits. Advances in Experimental Medicine and Biology 784 275-295. (https://doi. org/10.1007/978-1-4614-6199-9_13)

Soma KK, Rendon NM, Boonstra R, Albers HE \& Demas GE 2015 DHEA effects on brain and behavior: insights from comparative studies of aggression. Journal of Steroid Biochemistry and Molecular Biology 145 261-272. (https://doi.org/10.1016/j.jsbmb.2014.05.011)

Sonmezer M, Ozmen B, Cil AP, Ozkavukcu S, Tasci T, Olmus H \& Atabekoglu CS 2009 Dehydroepiandrosterone supplementation improves ovarian response and cycle outcome in poor responders. Reproductive Biomedicine Online 19 508-513. (https://doi.org/10.1016/j. rbmo.2009.06.006)

Spinder T, Spijkstra JJ, Van Den Tweel JG, Burger CW, Van Kessel H, Hompes PGA \& Gooren LJG 1989 The effects of long term testosterone administration on pulsatile luteinizing hormone secretion and on ovarian histology in eugonadal female to male transsexual subjects. Journal of Clinical Endocrinology and Metabolism 69 151-157. (https://doi.org/10.1210/jcem-69-1-151)

Steckelbroeck S, Jin Y, Gopishetty S, Oyesanmi B \& Penning TM 2004 Human cytosolic 3alpha-hydroxysteroid dehydrogenases of the aldoketo reductase superfamily display significant 3beta-hydroxysteroid dehydrogenase activity: implications for steroid hormone metabolism and action. Journal of Biological Chemistry 279 10784-10795. (https:// doi.org/10.1074/jbc.M313308200)

Sullivan SD \& Moenter SM 2004 Prenatal androgens alter GABAergic drive to gonadotropin-releasing hormone neurons: implications for a common fertility disorder. PNAS 101 7129-7134. (https://doi. org/10.1073/pnas.0308058101)

Sun B, Wang F, Sun J, Yu W \& Sun Y 2014 Basal serum testosterone levels correlate with ovarian response but do not predict pregnancy outcome in non-PCOS women undergoing IVF. Journal of Assisted Reproduction and Genetics 31 829-835. (https://doi.org/10.1007/ s10815-014-0246-8)

Suzuki T, Sasano H, Kimura N, Tamura M, Fukaya T, Yajima A \& Nagura H 1994 Immunohistochemical distribution of progesterone, androgen and oestrogen receptors in the human ovary during the menstrual cycle: relationship to expression of steroidogenic enzymes. Human Reproduction 9 1589-1595. (https://doi.org/10.1093/oxfordjournals. humrep.a138757)

Szoltys M \& Slomczynska M 2000 Changes in distribution of androgen receptor during maturation of rat ovarian follicles. Experimental and Clinical Endocrinology and Diabetes 108 228-234. (https://doi org/10.1055/s-2000-7747)

Tarlatzis BC, Zepiridis L, Grimbizis G \& Bontis J 2003 Clinical management of low ovarian response to stimulation for IVF: a systematic review. Human Reproduction Update 9 61-76. (https://doi. org/10.1093/humupd/dmg007)

Tartagni M, Cicinelli E, De Pergola G, Lavopa C, Di Naro E, De Salvia MA \& Loverro G 2010 Effect of finasteride on ovulation induction in nonresponder (hyperandrogenic) polycystic ovary syndrome (PCOS) women. Fertility and Sterility 94 247-249. (https://doi.org/10.1016/j. fertnstert.2009.01.150)

Tartagni MV, Alrasheed H, Damiani GR, Montagnani M, De Salvia MA, De Pergola G, Tartagni M \& Loverro G 2014 Intermittent low-dose Finasteride Administration is effective for treatment of hirsutism in adolescent girls: a pilot study. Journal of Pediatric and Adolescent Gynecology 27 161-165. (https://doi.org/10.1016/j.jpag.2013.09.010)

Taylor A 2003 ABC of subfertility: extent of the problem. BMJ $\mathbf{3 2 7}$ 434-436. (https://doi.org/10.1136/bmj.327.7412.434)

Teede HJ, Misso ML, Costello MF, Dokras A, Laven J, Moran L, Piltonen T, Norman RJ \& International PCOS Network 2018 Recommendations from the international evidence-based guideline for the assessment 
and management of polycystic ovary syndrome. Human Reproduction 33 1602-1618. (https://doi.org/10.1093/humrep/dey256)

Tsui KH, Lin LT, Horng HC, Chang R, Huang BS, Cheng JT \& Wang PH 2014 Gene expression of cumulus cells in women with poor ovarian response after dehydroepiandrosterone supplementation. Taiwanese Journal of Obstetrics and Gynecology 53 559-565. (https://doi. org/10.1016/j.tjog.2014.09.003)

Tsui KH, Lin LT, Chang R, Huang BS, Cheng JT \& Wang PH 2015 Effects of dehydroepiandrosterone supplementation on women with poor ovarian response: a preliminary report and review. Taiwanese Journal of Obstetrics and Gynecology 54 131-136. (https://doi.org/10.1016/j. tjog.2014.07.007)

Umayal B, Jayakody SN, Chandrasekharan NV, Wijesundera WS \& Wijeyaratne CN 2019 Polycystic ovary syndrome (PCOS) and kisspeptin - a Sri Lankan study. Journal of Postgraduate Medicine 65 18-23. (https://doi.org/10.4103/jpgm.JPGM_683_17)

Vendola KA, Zhou J, Adesanya OO, Weil SJ \& Bondy CA 1998 Androgens stimulate early stages of follicular growth in the primate ovary. Journal of Clinical Investigation 101 2622-2629. (https://doi.org/10.1172/ JCI2081)

Vendola K, Zhou J, Wang J, Famuyiwa OA, Bievre M \& Bondy CA 1999 Androgens promote oocyte insulin-like growth factor I expression and initiation of follicle development in the primate ovary. Biology of Reproduction 61 353-357. (https://doi.org/10.1095/ biolreprod61.2.353)

Venturoli S, Marescalchi O, Colombo FM, Macrelli S, Ravaioli B, Bagnoli A, Paradisi R \& Flamigni C 1999 A prospective randomized trial comparing low dose flutamide, finasteride, ketoconazole, and cyproterone acetate-estrogen regimens in the treatment of hirsutism. Journal of Clinical Endocrinology and Metabolism 84 1304-1310. (https://doi.org/10.1210/jcem.84.4.5591)

Villanueva EC \& Myers MG 2008 Leptin receptor signaling and the regulation of mammalian physiology. International Journal of Obesity 32 (Supplement 7) S8-S12. (https://doi.org/10.1038/ijo.2008.232)

Vlahos N, Papalouka M, Triantafyllidou O, Vlachos A, Vakas P, Grimbizis G, Creatsas G \& Zikopoulos K 2015 Dehydroepiandrosterone administration before IVF in poor responders: a prospective cohort study. Reproductive Biomedicine Online 30 191-196. (https://doi.org/10.1016/j.rbmo.2014.10.005)

Walters KA 2015 Role of androgens in normal and pathological ovarian function. Reproduction 149 R193-R218. (https://doi.org/10.1530/REP14-0517)

Walters KA \& Handelsman DJ 2018 Role of androgens in the ovary. Molecular and Cellular Endocrinology 465 36-47. (https://doi. org/10.1016/j.mce.2017.06.026)

Walters KA, Allan CM, Jimenez M, Lim PR, Davey RA, Zajac JD, Illingworth P \& Handelsman DJ 2007 Female mice haploinsufficient for an inactivated androgen receptor (AR) exhibit age-dependent defects that resemble the AR null phenotype of dysfunctional late follicle development, ovulation, and fertility. Endocrinology 148 3674-3684. (https://doi.org/10.1210/en.2007-0248)

Walters KA, Mctavish KJ, Seneviratne MG, Jimenez M, Mcmahon AC, Allan CM, Salamonsen LA \& Handelsman DJ 2009 Subfertile female androgen receptor knockout mice exhibit defects in neuroendocrine signaling, intraovarian function, and uterine development but not uterine function. Endocrinology 150 3274-3282. (https://doi. org/10.1210/en.2008-1750)

Walters KA, Allan CM \& Handelsman DJ 2012a Rodent models for human polycystic ovary syndrome. Biology of Reproduction 86 1-12. (https://doi.org/10.1095/biolreprod.111.097808)

Walters KA, Middleton LJ, Joseph SR, Hazra R, Jimenez M, Simanainen U, Allan CM \& Handelsman DJ 2012b Targeted loss of androgen receptor signaling in murine granulosa cells of preantral and antral follicles causes female subfertility. Biology of Reproduction 87 151. (https://doi. org/10.1095/biolreprod.112.102012)
Walters KA, Bertoldo MJ \& Handelsman DJ 2018a Evidence from animal models on the pathogenesis of PCOS. Best Practice and Research: Clinical Endocrinology and Metabolism 32 271-281. (https://doi. org/10.1016/j.beem.2018.03.008)

Walters KA, Edwards MC, Tesic D, Caldwell ASL, Jimenez M, Smith JT \& Handelsman DJ 2018b The role of central androgen receptor actions in regulating the hypothalamic-pituitary-ovarian axis. Neuroendocrinology 106 389-400. (https://doi.org/10.1159/000487762)

Walters KA, Eid S, Edwards MC, Thuis-Watson R, Desai R, Bowman M, Marren AJ \& Handelsman DJ 2019 Steroid profiles by liquid chromatography-mass spectrometry of matched serum and single dominant ovarian follicular fluid from women undergoing IVF. Reproductive Biomedicine Online 38 30-37. (https://doi.org/10.1016/j. rbmo.2018.10.006)

Wang H, Andoh K, Hagiwara H, Xiaowei L, Kikuchi N, Abe Y, Yamada K, Fatima R \& Mizunuma H 2001 Effect of adrenal and ovarian androgens on type 4 follicles unresponsive to FSH in immature mice. Endocrinology 142 4930-4936. (https://doi.org/10.1210/ endo.142.11.8482)

Weil S, Vendola K, Zhou J \& Bondy CA 1999 Androgen and folliclestimulating hormone interactions in primate ovarian follicle development. Journal of Clinical Endocrinology and Metabolism $\mathbf{8 4}$ 2951-2956. (https://doi.org/10.1210/jcem.84.8.5929)

Westergaard LG, Laursen SB \& Andersen CY 2000 Increased risk of early pregnancy loss by profound suppression of luteinizing hormone during ovarian stimulation in normogonadotrophic women undergoing assisted reproduction. Human Reproduction 15 1003-1008. (https://doi.org/10.1093/humrep/15.5.1003)

Wilson CM \& McPhaul MJ 1996 A and B forms of the androgen receptor are expressed in a variety of human tissues. Molecular and Cellular Endocrinology 120 51-57. (https://doi.org/10.1016/03037207(96)03819-1)

Wiser A, Gonen O, Ghetler Y, Shavit T, Berkovitz A \& Shulman A 2010 Addition of dehydroepiandrosterone (DHEA) for poor-responder patients before and during IVF treatment improves the pregnancy rate: a randomized prospective study. Human Reproduction $\mathbf{2 5}$ 2496-2500. (https://doi.org/10.1093/humrep/deq220)

Wu XY, Li ZL, Wu CY, Liu YM, Lin H, Wang SH \& Xiao WF 2010 Endocrine traits of polycystic ovary syndrome in prenatally androgenized female Sprague-Dawley rats. Endocrine Journal $\mathbf{5 7}$ 201-209. (https://doi.org/10.1507/endocri.K09E-205)

Wu S, Chen Y, Fajobi T, Divall SA, Chang C, Yeh S \& Wolfe A 2014 Conditional knockout of the androgen receptor in gonadotropes reveals crucial roles for androgen in gonadotropin synthesis and surge in female mice. Molecular Endocrinology 28 1670-1681. (https://doi. org/10.1210/me.2014-1154)

Xiao S, Li Y, Long L, Luo C \& Mai Q 2016 Basal serum testosterone levels correlate with ovarian reserve and ovarian response in cycling women undergoing in vitro fertilization. Gynecological Endocrinology 32 51-54. (https://doi.org/10.3109/09513590.2015.1076784)

Xu B, Li Z, Yue J, Jin L, Li Y, Ai J, Zhang H \& Zhu G 2014 Effect of dehydroepiandrosterone administration in patients with poor ovarian response according to the Bologna criteria. PLOS ONE 9 e99858. (https://doi.org/10.1371/journal.pone.0099858)

Yang JL, Zhang CP, Li L, Huang L, Ji SY, Lu CL, Fan CH, Cai H, Ren Y, Hu ZY, et al. 2010 Testosterone induces redistribution of forkhead box-3a and down-regulation of growth and differentiation factor 9 messenger ribonucleic acid expression at early stage of mouse folliculogenesis. Endocrinology 151 774-782. (https://doi.org/10.1210/ en.2009-0751)

Yarali H, Esinler I, Polat M, Bozdag G \& Tiras B 2009 Antagonist/ letrozole protocol in poor ovarian responders for intracytoplasmic sperm injection: a comparative study with the microdose flare-up protocol. Fertility and Sterility 92 231-235. (https://doi.org/10.1016/j. fertnstert.2008.04.057) https://joe.bioscientifica.com

https://doi.org/10.1530/JOE-19-0096 (c) 2019 Society for Endocrinology Published by Bioscientifica Ltd. Printed in Great Britain 
Yeh S, Tsai MY, Xu Q, Mu XM, Lardy H, Huang KE, Lin H, Yeh SD, Altuwaijri S, Zhou X, et al. 2002 Generation and characterization of androgen receptor knockout (ARKO) mice: an in vivo model for the study of androgen functions in selective tissues. PNAS $\mathbf{9 9}$ 13498-13503. (https://doi.org/10.1073/pnas.212474399)

Yeung TW, Chai J, Li RH, Lee VC, Ho PC \& Ng EH 2014 A randomized, controlled, pilot trial on the effect of dehydroepiandrosterone on ovarian response markers, ovarian response, and in vitro fertilization outcomes in poor responders. Fertility and Sterility 102 108.e1-115.e1. (https://doi.org/10.1016/j.fertnstert.2014.03.044)

Yildiz BO 2008 Oral contraceptives in polycystic ovary syndrome: riskbenefit assessment. Seminars in Reproductive Medicine 26 111-120. (https://doi.org/10.1055/s-2007-992931)

Yuan X, Hu T, Zhao H, Huang Y, Ye R, Lin J, Zhang C, Zhang H, Wei G, Zhou $\mathrm{H}$, et al. 2016 Brown adipose tissue transplantation ameliorates polycystic ovary syndrome. PNAS $\mathbf{1 1 3}$ 2708-2713. (https://doi. org/10.1073/pnas.1523236113)

Zawadzki JK \& Dunaif A 1992 Diagnostic criteria for polycystic ovary syndrome: towards a rational approach. In Polycystic Ovary Syndrome. Eds A Dunaif, HR Givens, FP Haseltine \& GR Merriam. Boston, MA, USA: Blackwell Scientific Publications.

Zhang HH, Xu PY, Wu J, Zou WW, Xu XM, Cao XY \& Wei LZ 2014 Dehydroepiandrosterone improves follicular fluid bone morphogenetic protein-15 and accumulated embryo score of infertility patients with diminished ovarian reserve undergoing in vitro fertilization: a randomized controlled trial. Journal of Ovarian Research 7 93. (https://doi.org/10.1186/s13048-0140093-3)

Zhang M, Niu W, Wang Y, Xu J, Bao X, Wang L, Du L \& Sun Y 2016 Dehydroepiandrosterone treatment in women with poor ovarian response undergoing IVF or ICSI: a systematic review and metaanalysis. Journal of Assisted Reproduction and Genetics 33 981-991. (https://doi.org/10.1007/s10815-016-0713-5)

Zimmerman Y, Eijkemans MJ, Coelingh Bennink HJ, Blankenstein MA \& Fauser BC 2014 The effect of combined oral contraception on testosterone levels in healthy women: a systematic review and meta-analysis. Human Reproduction Update 20 76-105. (https://doi. org/10.1093/humupd/dmt038)

Zulian E, Sartorato P, Benedini S, Baro G, Armanini D, Mantero F \& Scaroni C 2005 Spironolactone in the treatment of polycystic ovary syndrome: effects on clinical features, insulin sensitivity and lipid profile. Journal of Endocrinological Investigation 28 49-53. (https://doi. org/10.1007/BF03345529)

Zumoff B, Strain GW, Miller LK \& Rosner W 1995 Twenty-four-hour mean plasma testosterone concentration declines with age in normal premenopausal women. Journal of Clinical Endocrinology and Metabolism 80 1429-1430. (https://doi.org/10.1210/ jcem.80.4.7714119)

Received in final form 2 May 2019

Accepted 20 May 2019

Accepted Preprint published online 23 May 2019 (c) 2019 Society for Endocrinology Published by Bioscientifica Ltd. 